\title{
CAMA
}

Centre for Applied Macroeconomic Analysis

\section{Age-Dependent Risk Aversion: Re-evaluating Fiscal Policy Impacts of Population Ageing}

\section{CAMA Working Paper 88/2020 October 2020}

\section{Phitawat Poonpolkul}

Crawford School of Public Policy, ANU

Centre for Applied Macroeconomic Analysis, ANU

\section{Abstract}

This study revisits optimal fiscal policies in response to population ageing by introducing an age-dependent increasing risk aversion assumption into an OLG model with risksensitive preferences. Under this specification, the policy evaluation factors in the welfare cost of policy-induced uncertainties and suggests that, based on future generations' welfare, financing population ageing by either reducing social security benefits or extending the retirement age may not be as strongly preferred over raising the payroll tax rate as prior studies have suggested. Varying risk aversion also emphasizes the role of precautionary savings that causes individuals to respond slightly differently to changes in demographic structures and price variables. This, in turn, influences the redistribution of life-cycle variables and transition dynamics of aggregate variables. 


\title{
Keywords
}

Overlapping generations model, Increasing risk aversion, Non-expected utility

\author{
JEL Classification
}

D15, D81, E62, J11

Address for correspondence:

(E) cama.admin@anu.edu.au

\section{ISSN 2206-0332}

The Centre for Applied Macroeconomic Analysis in the Crawford School of Public Policy has been established to build strong links between professional macroeconomists. It provides a forum for quality macroeconomic research and discussion of policy issues between academia, government and the private sector.

The Crawford School of Public Policy is the Australian National University's public policy school, serving and influencing Australia, Asia and the Pacific through advanced policy research, graduate and executive education, and policy impact. 


\title{
Age-Dependent Risk Aversion: Re-evaluating Fiscal Policy Impacts of Population Ageing*
}

\author{
Phitawat Poonpolkul ${ }^{\dagger}$
}

October 2, 2020

\begin{abstract}
This study revisits optimal fiscal policies in response to population ageing by introducing an age-dependent increasing risk aversion assumption into an OLG model with risk-sensitive preferences. Under this specification, the policy evaluation factors in the welfare cost of policy-induced uncertainties and suggests that, based on future generations' welfare, financing population ageing by either reducing social security benefits or extending the retirement age may not be as strongly preferred over raising the payroll tax rate as prior studies have suggested. Varying risk aversion also emphasizes the role of precautionary savings that causes individuals to respond slightly differently to changes in demographic structures and price variables. This, in turn, influences the redistribution of life-cycle variables and transition dynamics of aggregate variables.
\end{abstract}

Keywords: Overlapping generations model, Increasing risk aversion, Non-expected utility

JEL Codes: D15, D81, E62, J11

${ }^{*}$ I gratefully acknowledge financially support by the Australia Research Council Centre of Excellence in Population Ageing Research (CE170100005). I would like to express my gratitude to Warwick McKibbin, Renee McKibbin, and Larry Liu for their guidance and valuable suggestions on this work. I would also like to thank George Kudrna and Yiyong Cai for the useful comments.

${ }^{\dagger}$ Centre for Applied Macroeconomic Analysis, Crawford School of Public Policy, Australian National University 


\section{Introduction}

Population ageing poses challenges to economic growth and fiscal sustainability. Changes in mortality rates and factor prices within the economy will affect household decisions to consume and save. This, together with the changes in the demographic structure, will influence the path of the aggregate economy. A decreasing share of workers and an increasing share of retirees also reduce the government tax revenue per capita while increase the government spending on social security. This can cause fiscal policy to be unsustainable without a well-planned social security reform. Delving into this issue, this study examines macroeconomic and welfare implications of shifting demographics while revisiting the conventional underlying assumption of constant risk aversion in favour of using age-dependent risk aversion.

Based on the assumption of heterogeneity in age, the dynamic overlapping generations (OLG) model has been pre-eminent in analysing the impacts of demographic changes, particularly on the issues of optimal pension, social contribution scheme as well as demographic-induced macroeconomic changes. The seminal work by Auerbach and Kotlikoff (1987) (AK henceforth) studied the sustainability of the social security system under a demographic transition. They introduced a realistic 55-period dynamic general equilibrium OLG model that is flexible enough to examine different aspects of fiscal policies on intertemporal general equilibria and serves as a groundwork for later studies, including the model used in the present paper.

Based on the AK-type OLG model, a wide range of subsequent studies covered the topics of social security privatization (e.g., Kotlikoff et al. (1999), Nishiyama and Smetters (2007)), welfare and macroeconomic effects of different tax reforms (e.g., De Nardi et al. (1999), Huggett and Ventura (1999), Altig et al. (2001), Vogel et al. (2017)), and optimal fiscal scheme (e.g., Imrohoroglu et al. (1995), Gottardi et al. (2015)), for instance. Each study evolved from the original AK model in terms of their model specifications and assumptions such as idiosyncratic wage shocks, endogenous human capital accumulation, and more realistic government and population structures.

Most relevant to this study are the works conducted by Nishiyama (2015) and Kitao (2014). Both of which study macroeconomic and welfare impacts of population ageing under different policy alternatives using a heterogeneous-agent OLG model with idiosyncratic wage and mortality shocks, the specifications that are also present in the current paper. Kitao (2014) developed a model with an endogenous labour supply at both intensive and extensive margins and followed French (2005) in determining social security benefits as a concave piecewise linear function of the Average Indexed Monthly Earnings (AIME). She presented four sustainable self-financed policy options in response to demographic ageing and concluded that cutting the replacement rate and increasing the normal retirement age yield higher welfare for future generations compared to increasing the payroll taxes. Nishiyama (2015) used a model with a detailed social security system and a new calibration procedure and forecasted a large fiscal gap under the U.S. Social Security Administration (SSA)'s population projection, the size of which depending on how the government finances its social security spending. He found the welfare results to be consistent with Kitao (2014), i.e., cutting social security benefit fares better than raising the payroll tax rate. However, the current paper finds that such a conclusion doesn't hold under increasing age-dependent 
risk aversion.

Despite the abundance of research around the issue of demographic changes and fiscal policy, one common assumption underlying all the findings is that risk aversion is constant and independent of age. This study argues that such an assumption may be unrealistic, especially in an OLG model that aims to account for age-specific behaviours. Among these behaviours, attitude toward risk determines how much an individual wants to consume, save, and how that individual's welfare is affected by shocks. Any of these channels consequently influence prices and macroeconomic variables generated from economic models. In fact, a few studies have examined the issue of risk aversion on the macroeconomy, although not with a general equilibrium OLG model. Preferences with increasing risk aversion produce equity premium, savings and portfolio share behaviour that are more consistent with the U.S. data, suggested DaSilva et al. (2019) using three-period OLG model without the production sector. Tallarini Jr (2000) considered a business cycle model without overlapping generations and showed that increasing risk aversion, although it does not significantly affect aggregate quantity variables, can improve the asset market predictions and increase the welfare cost of the business cycle. Some of Tallarini Jr (2000)'s findings are consistent with the results of the OLG model of this study as will be later discussed.

Studies have also shown that people's preferences towards risk vary depending on various characteristics, one of which is demographics, particularly with respect to age. To estimate and study risk aversion, there are mainly two elicitation methods used. The first method bases its estimation on Arrow (1965) and Pratt (1964)'s concept of risk aversion, expressed as the elasticity of marginal utility with respect to wealth and can be derived from the portfolio choice data. Although this concept is very tractable, allowing for the quantitative estimation, it is derived from the HARA-class utility function (Blume and Friend (1975) and Pålsson (1996)) and therefore does not apply to the non-expected utility used in the present study where the timing of the resolution of uncertainty is crucial (Kreps and Porteus, 1978). There are also still some controversies in the findings, and it can be said that the results differ according to what estimation approaches were used, how underlying variables were measured and defined, and over what time periods were the studies undertaken (Meyer and Meyer (2005) and Conine et al. (2017)). Nevertheless, among the existing literature using the HARA-class utility, most studies have found risk aversion to increase with age, with the exception of those that do not categorize housing as a risky asset that find risk aversion to decrease until the age of 65 and increase thereafter ${ }^{1}$.

The second elicitation method is economic experimentation that estimates risk aversion from an individual's decision towards different pay-off structures. To estimate

\footnotetext{
1 Morin and Suarez (1983) used a categorical variable for households above age 65 and suggested that risk aversion increases with age. Pålsson (1996) recognized that households compose different risky portfolios according to varying demographic and socioeconomic characteristics. However, age is the only significant variable with the coefficient suggesting that risk aversion increases with age. Riley Jr and Chow (1992) used a dummy variable for households over age 65 and concluded that relative risk aversion decreases with age until 65 and increases afterwards. However, they did not include housing and bonds as risky assets. Similar to Riley Jr and Chow (1992), Halek and Eisenhauer (2001) used a dummy variable to represent those above age 65 and found relative risk aversion to decrease with age and increase after age 65. Bellante and Green (2004) specifically examined households with at least one member aged 70 or over and found relative risk aversion tend to increase with age at any given level of wealth.
} 
age-dependent risk aversion with non-expected utility, this study refers to the study done by Albert and Duffy (2012), which applied the elicitation strategy of the lottery choice menu proposed by Holt and Laury (2002) to two different age groups. They showed that older adults are more risk-averse than younger adults, consistent with another experiment conducted by Dohmen et al. (2011) based on a 10-point scale as well as the study by Roalf et al. (2011). The experiment results are then converted into risk aversion values used in this study by assuming that the experiment participants have risk-sensitive preferences when making decisions and their behaviour towards next period value function behave in the same manner as towards monetary pay-off from the paired lottery experiment.

This paper presents a heterogeneous-agent OLG model with idiosyncratic wage and mortality shocks, endogenous saving and labour supply, and risk-sensitive preferences with two risk aversion assumptions, one that is constant and another that is increasing with age, to evaluate impacts on distributions of life-cycle variables, transition dynamics, and, most importantly, the welfare impacts of each generation over time. Risk-sensitive preferences are chosen as they are the only class of recursive preferences that is monotonic (Bommier et al., 2017), enabling it to rule out dominated strategies and providing consistent comparative statics regarding the impacts of varying risk aversion on precautionary savings and welfare ${ }^{2}$. This study adopts the government structure and the social security benefits function from the work of Kitao (2014) and follows the general strategy to solve for the equilibrium transition path from the work of Nishiyama (2015). Three self-financing policy alternatives are evaluated under the SSA's median population projection, including increasing the payroll tax rate, cutting social security benefits, and extending the retirement age.

This study finds that when using the assumption of age-dependent increasing risk aversion under the current preferences specification, the policy evaluation emphasizes the welfare cost from policy-induced uncertainties. Importantly, the welfare rankings of policies found in previous studies can change once age-dependent risk aversion is incorporated. Reducing social security benefits and extending the retirement age may not be strongly preferred over increasing the payroll tax rate in terms of welfare improvement because the former result in higher uncertainties. Nevertheless, raising the retirement age yields better results both in terms of future welfare improvement and economic expansion when compared with reducing benefits. Under an alternative calibration with higher idiosyncratic labour productivity and a social security distribution, which may be more realistic assumptions as argued in Section A.2 and A.3, extending the retirement age is more favourable based on future generations' welfare while the adverse welfare impacts on the current generations also diminish. The assumption of increasing risk aversion also leads to slightly higher life-cycle precautionary savings and labour supply, subsequently leading to more desirable transition dynamics of per capita output.

The rest of the paper is organized as follows. Section 2 describes the model structure and briefly justifies the reasons for using the risk-sensitive preferences. Section 3 details the strategies of calibrating the model parameters. Section 4 compares numerical results under two risk aversion assumptions and three policy options regarding the redistribution of life-cycle variables, transition dynamics, and social welfare impacts.

\footnotetext{
${ }^{2}$ See detailed discussion in Bommier et al. (2017), Bommier and Grand (2018), and Bommier et al. (2020)
} 
Section 5 discusses the implications on fiscal policy implementation and concludes.

\section{The model}

The model economy consists of overlapping-generation households whose utility is characterized by risk-sensitive preferences. Time is discrete and the price of the consumption good is the numeraire and is normalized to 1 . The government is assumed to be able to credibly commit to its policies and operate a pay-as-you-go social security system as proposed by Kitao (2014).

\subsection{Demographics}

During each one year period $t$, the economy consists of a continuum of households that are heterogeneous with respect to their age, $j=1, \ldots, J$, beginning-of-period asset, $a_{t}^{j} \in A=\left[a_{\text {min }}, \infty\right)$, idiosyncratic productivity shock, $\eta_{t}^{j} \in H=[0, \infty)$, ageearning profile, $e_{j} \in E=[0, \infty)$, inherent fixed productivity (or education level) $\theta \in \Theta=[0, \infty)$, and Average Indexed Monthly Earnings (AIME), $\kappa \in K=[0, \infty)$.

There are 101 overlapping generations aged 0 to 100 in the economy at each point in time $t$. Individuals aged 0 to 19 live to the next period with certainty. With no initial wealth, they start to make economic decisions at the age of 20, work until the age of $J_{R}=67$ and die with certainty by the end of age $J=100$. Once retired, they receive social security benefits, $\chi \in X=[0, \infty)$ based on their AIME, which is determined by their working income history (see the calculation in section 3.5). The benefit amount remains the same after the retirement for the same individual but differ across eligible individuals in any given year depending on the timing of their retirement. Between age 20 to 100, living individuals survive from age $j-1$ to age $j$ at time $t$ with probability $\xi_{t}^{j}$. Let $N_{t}^{j}$ be the amount of population aged $j$ at time $t$, the population dynamics can be written as

$$
N_{t+1}^{j+1}=\xi_{t+1}^{j+1} N_{t}^{j} \text { for } j>20
$$

and the number of new entrants to the economy in each period can be estimated according to age- and time-specific fertility rates as

$$
N_{t}^{20}=\sum_{j} f_{t}^{j} N_{t}^{j}
$$

where $f_{t}^{j}$ is the fertility rate of cohort $j$ at time $t$ and $N_{t=2018}^{20}$ is normalized to 1 .

The total population $N_{t}$ is the sum of all cohorts alive at period $t$ :

$$
N_{t}=\sum_{j=1}^{J} N_{t}^{j}
$$

with $n_{t}=\frac{N_{t}}{N_{t-1}}-1$ representing time- $t$ total population growth rate. The share of cohort of age $j$ in the total population at time $t$ is represented by $m_{t}^{j}$ where $\sum_{j=1}^{J} m_{t}^{j}$ are normalized to be identical across time so that the individual variables apart from working hours are adjusted by $(1+\mu)^{-t}$ and the aggregate variables are adjusted by $[(1+n)(1+\mu)]^{-t}$ where $\mu$ is the labour augmenting productivity growth rate. 


\subsection{Heterogeneity and state variables}

An individual's heterogeneity is represented by the states $x_{t}=\{j, a, \theta, \eta, e, \kappa\}$, where $a$ is the beginning of period asset holdings, and $\{\theta, \eta, e, \kappa\}$ determine labour productivity and AIME as explained above.

Let $X_{t}=\left\{\phi_{t}\left(x_{t}\right)\right\}$ denote the aggregate state of economy at time $t$ where $\phi_{t}\left(x_{t}\right)$ represents the mass of household with individual state $x_{t}$ and satisfies $\sum_{j=1}^{J} \int_{A \times \Theta \times H} d \phi_{t}(j, a, \theta, \eta, e)=$ $N_{t}$.

Let $\Psi_{t}=\left\{G_{t}, D_{t}, \chi, \tau_{t}^{s}, \tau_{t}^{k}, \tau_{t}^{l}, \tau_{t}^{c}, y^{s}\right\}$ be government policy schedule where $G_{t}$ and $D_{t}$ are government spending and government debt, $\left\{\tau_{t}^{s}, \tau_{t}^{k}, \tau_{t}^{l}, \tau_{t}^{c}\right\}$ are social security tax, capital income tax, labour income tax and consumption tax respectively, and $y^{s}$ is the social security maximum taxable earnings.

The population at time $t$ is characterized by $\Phi_{t}=\left\{\left(N_{t}^{j}\right)_{j=1}^{J},\left(f_{t}^{j}\right)_{j=1}^{J},\left(\xi_{t}^{j}\right)_{j=1}^{J}\right\}$ which is assumed to be deterministic and known to all individuals.

\subsection{Households}

\subsubsection{Preferences}

This study considers the special case of a recursive non-expected utility by Epstein and Zin (1989) and Weil (1990)(EZW) where the intertemporal elasticity of substitution is equal to one. Following Tallarini Jr (2000), the utility function can be transformed into a risk-sensitive preferences similar to the specification used by L. P. Hansen and Sargent (1995), which possesses desirable properties for this analysis. The monotonic property offers intuitive and consistent interpretation in regard to comparative statistics on precautionary savings with different degrees of risk aversion. The incorporation of future variances into individual's optimal decisions also plays an important role to capture welfare impacts of age-dependently risk averse individuals when faced with population ageing and corresponding policy responses.

At time t, utility of a continuum of age-j individuals is given by the following recursion

$$
W\left(U\left(c_{t}^{j}, 1-l_{t}^{j}\right), I\right)= \begin{cases}{\left[(1-\beta) U\left(c_{t}^{j}, 1-l_{t}^{j}\right)^{1-\rho}+\beta I^{1-\rho}\right]^{\frac{1}{1-\rho}}} & \text { if } 0<\rho \neq 1 \\ U\left(c_{t}^{j}, 1-l_{t}^{j}\right)^{1-\beta} I^{\beta} & \text { if } \rho=1,\end{cases}
$$

where $W$ is a time aggregator function, $1 / \rho$ captures an intertemporal elasticity of substitution, $\beta \in(0,1)$ is a constant discount factor, and $I$ is a certainty equivalent of the next-period random value function, $V_{t+1}$, contingent on current states of age-j idiosyncratic labor productivity shock $\eta_{t}^{j}$

$$
I\left(V_{t+1}^{j+1}\right)=\mathbb{E}_{t}\left(V_{t+1}^{j+1}\left(1-\gamma^{j}\right) \mid \eta_{t}^{j}\right)^{\frac{1}{1-\gamma^{j}}} .
$$

The coefficients of relative risk aversion of age-j household are represented by $\gamma^{j}$. When $\rho=\gamma$, EZW preferences reduce to standard time-additive expected utility.

Consumers derive utility from the composite good between consumption $c_{t}^{j}$ and leisure $\left(1-l_{t}^{j}\right)$ which is expressed in the form of Cobb-Douglass utility function

$$
U\left(c_{t}^{j}, 1-l_{t}^{j}\right)=\left(c_{t}^{j}\right)^{\nu}\left(1-l_{t}^{j}\right)^{1-\nu},
$$

where $\nu$ is the taste parameter of consumption. 
With an assumption of unit elasticity of substitution, we can convert EZW preferences into risk-sensitive preferences by following the approach of Tallarini Jr (2000). The recursive utility becomes

$$
V_{t}^{j}=\left[\left(c_{t}^{j}\right)^{\nu}\left(1-l_{t}^{j}\right)^{1-\nu}\right]^{1-\beta}\left[\mathbb{E}_{t}\left(V_{t+1}^{j+1}\left(1-\gamma^{j}\right) \mid \eta_{t}^{j}\right)^{\frac{1}{1-\gamma^{j}}}\right]^{\beta} .
$$

Taking logs and rearrange gives

$$
\frac{\ln V_{t}^{j}}{1-\beta}=\left(\nu \ln c_{t}^{j}+(1-\nu) \ln \left(1-l_{t}^{j}\right)\right)+\frac{\beta}{\left(1-\gamma^{j}\right)(1-\beta)} \ln \mathbb{E}_{t}\left(V_{t+1}^{j+1}\left(1-\gamma^{j}\right) \mid \eta_{t}^{j}\right) .
$$

By transforming $\tilde{V}_{t}^{j}=\frac{\ln V_{t}^{j}}{(1-\beta)}$ and $\psi^{j}=-(1-\beta)\left(1-\gamma^{j}\right)$, the above equation can be re-written as

$$
\tilde{V}_{t}^{j}=\left(\nu \ln c_{t}^{j}+(1-\nu) \ln \left(1-l_{t}^{j}\right)\right)-\frac{\beta}{\psi^{j}} \ln \mathbb{E}_{t}\left(e^{-\psi^{j} \tilde{V}_{t+1}^{j+1}} \mid \eta_{t}^{j}\right)
$$

which resembles risk-sensitive preferences of L. P. Hansen and Sargent (1995) and Weil (1993). The risk-sensitivity parameter $\psi^{j}$ measures degrees of risk aversion towards future utility of age $j$ agents, in contrast to relative risk aversion with respect to atemporal wealth gamble, $\gamma$, where wealth is measured in terms of composite commodity $\left(c_{t}^{j}\right)^{\nu}\left(1-l_{t}^{j}\right)^{1-\nu}$.

The functional form of the certainty equivalent $(\mathrm{CE})$ of the risk-sensitive preferences in (9) can also be called the entropic risk measure which represents the relative entropy of the next-period value functions. To interpret how the risk aversion parameter affects the value of the $\mathrm{CE}$, we can draw implication by using the Taylor expansions. Let $\rho^{\text {ent }}(X)$ represent the entropic risk measure which is written as

$$
\rho^{e n t}\left(V_{t+1}^{j+1}\right)=\frac{1}{\psi^{j}} \ln \left(\mathbb{E}\left(e^{-\psi^{j}} V_{t+1}^{j+1}\right)\right) .
$$

Applying the Taylor expansions gives

$$
\rho^{e n t}\left(V_{t+1}^{j+1}\right)=\mathbb{E}\left(V_{t+1}^{j+1}\right)-\frac{\psi^{j}}{2} \operatorname{Var}\left(V_{t+1}^{j+1}\right)
$$

which suggests that households consider both first and second moments of the nextperiod value function. In other words, they care about the dispersion of their lifetime utility. The second term could be interpreted as a penalty function on randomness of $V_{t+1}^{j+1}$, with a degree of penalty depending on the value of parameter $\psi^{j}$. Agents are risk-averse towards future utilities when $\psi^{j}>0$ and are risk-loving when $\psi^{j}<0$. When $\psi \rightarrow 0$, risk-sensitive preferences in (9) convert into von Neumann-Morgenstern expected utility, in which case the risk aversion in future composite commodity has a direct relationship with the intertemporal elasticity of substitution.

\subsubsection{Budget constraints}

Each individual is born with no wealth and is endowed with one disposable unit of time to be allocated to leisure, $\left(1-l_{t}^{j}\right)$, or supplying labour, $l_{t}^{j}$, which earns a wage rate, $w_{t}$, per each efficiency unit. Labour earnings is determined by $w_{t} h^{j} l_{t}^{j}$ where 
productive efficiency unit $h^{j}$ is assumed to be a function of deterministic age-earning profile, $e_{j}$, an inherent productivity effect or education level, $\theta$, and an idiosyncratic productivity component, $\eta^{j}$, which is represented by

$$
\begin{aligned}
h^{j} & = \begin{cases}e^{j} \cdot \exp \left[\theta+\eta^{j}\right] & \text { for } j \leq J_{R} \\
0 & \text { for } j \geq J_{R}\end{cases} \\
\eta^{j+1} & =\rho \eta^{j}+\epsilon^{j+1} \quad \text { with } \quad \epsilon^{j+1} \sim N\left(0, \sigma_{\epsilon}^{2}\right),
\end{aligned}
$$

where $\rho$ represents autocorrelation from stochastic productivity of age $j$ to age $j+1$. Individuals also receive saving income determined by an asset holding at the beginning of the period, $a_{t}^{j}$, and an interest rate, $r_{t}$.

Working individuals pay a proportional social security tax $\tau^{s}$ on their earnings up to the maximum taxable amount $y_{t}^{s}$, and receive social security benefit, $\chi$, after retirement. Following Kitao (2014), the amount of social security benefit is determined as a concave function of an individual's average lifetime earnings. Individuals also pay taxes on labour income, capital income, and consumption at the rates $\tau^{l}, \tau^{k}$ and $\tau^{c}$ respectively. Without annuity markets, the assets of the deceased are equally distributed among living individuals as accidental bequests, $q_{t}$. Households' budget constraints can be written as

$$
\begin{aligned}
a_{t+1}^{j+1} & =\frac{1}{1+\mu}\left[\left(1+r_{t}\right) a_{t}^{j}+w_{t} h^{j} l_{t}^{j}+q_{t}+\chi-T(x)-c_{t}^{j}\right] \\
T(x) & =\tau^{c} c_{t}^{j}+\tau^{k} r_{t} a_{t}^{j}+\tau^{l} w_{t} h^{j} l_{t}^{j}+\tau^{s} \min \left\{w_{t} h^{j} l_{t}^{j}, y_{t}^{s}\right\}
\end{aligned}
$$

where $a_{t+1}^{j+1}$ is a saving at the beginning of next period and $c_{t}^{j}$ is a consumption of household $j$ at time $t$. The labour augmenting productivity growth is represented by $\mu$. Households cannot have negative savings, i.e., $a_{t}^{j} \geq 0$.

\subsubsection{Dynamic programming problem}

Each household in every age cohort chooses a stream of consumption, labour supplies, and next-period savings to solve the dynamic programming problem. Let $V\left(x, X_{t} ; \Phi_{t}, \Psi_{t}\right)$ be the value function. The Bellman equation can be written as

$$
\begin{aligned}
V\left(x, X_{t} ; \Phi_{t}, \Psi_{t}\right) & =\max _{\left\{c_{t}^{j}, l_{t}^{j}, a_{t+1}^{j+1}\right\}}\left\{\left(\nu \ln c_{t}^{j}+(1-\nu) \ln \left(1-l_{t}^{j}\right)\right)\right. \\
& \left.-\frac{\beta \xi^{j+1}}{\psi^{j}} \ln \mathbb{E}_{t}\left(e^{-\psi^{j} V\left(x_{t+1}, X_{t+1} ; \Phi_{t+1}, \Psi_{t+1}\right)} \mid \eta_{t}^{j}\right)\right\}
\end{aligned}
$$

subject to the following constraints

$$
\begin{aligned}
& a_{t+1}^{j+1}=\frac{1}{1+\mu}\left[\left(1+r_{t}\right) a_{t}^{j}+w_{t} h^{j} l_{t}^{j}+q_{t}+\chi-T\left(x_{t}\right)-c_{t}^{j}\right] \\
& T\left(x_{t}\right)=\tau^{c} c_{t}^{j}+\tau^{k} r_{t} a_{t}^{j}+\tau^{l} w_{t} h^{j} l_{t}^{j}+\tau^{s} \min \left\{w_{t} h^{j} l_{t}^{j}, y_{t}^{s}\right\}
\end{aligned}
$$


$\kappa_{t+1}= \begin{cases}\kappa_{t}+\frac{y_{L, t}}{35} & \text { for } 20 \leq j \leq 55 \\ \kappa_{t}+\max \left\{0, \frac{y_{L, t}-e_{t}}{35}\right\} & \text { for } 55<j \leq J_{R}\end{cases}$
$y_{L, t}=\min \left\{w_{t} h^{j} l_{t}^{j}, y_{t}^{s}\right\}$

$h^{j}= \begin{cases}e^{j} \cdot \exp \left[\theta+\eta^{j}\right] & \text { for } j \leq J_{R} \\ 0 & \text { for } j \geq J_{R}\end{cases}$

$\eta^{j+1}=\rho \eta^{j}+\epsilon^{j+1} \quad$ with $\quad \epsilon^{j+1} \sim N\left(0, \sigma_{\epsilon}^{2}\right)$

$c_{t}^{j}>0, \quad 0 \leq l_{t}^{j} \leq 1, \quad a_{t}^{j}>0$

where $y_{L, t}=\min \left\{w_{t} h^{j} l_{t}^{j}, y_{t}^{s}\right\}$ is the covered earnings.

\subsubsection{First-order conditions}

The first-order conditions of the Bellman equation with respect to current-period consumption, labour, and the next-period savings are

$$
\begin{gathered}
\frac{\nu}{c_{t}^{j}}=\frac{1}{1+\mu} \lambda\left(1+\tau^{c}\right) \\
\frac{1-\nu}{1-l_{t}^{j}}=\frac{1}{1+\mu} \lambda\left[\left(1-\tau^{l}-\mathbb{1}_{s} \tau^{s}\right) w_{t}^{j} h^{j}\right] \\
\beta \xi^{j+1} \frac{1}{\int_{\mathbb{R}^{+}} e^{-\psi^{j}} V_{t+1}^{j+1} v\left(d x_{t+1} \mid \eta_{t}^{j}\right)} \int_{\mathbb{R}^{+}} e^{-\psi^{j} V_{t+1}^{j+1}} \frac{\partial V_{t+1}^{j+1}}{\partial a_{t+1}^{j+1}} v\left(d x_{t+1} \mid \eta_{t}^{j}\right)=\lambda
\end{gathered}
$$

where $\mathbb{1}_{s}$ is 1 when $w_{t}^{j} h^{j} l_{t}^{j} \leq y_{t}^{s}$ and is 0 otherwise.

Applying the envelope theorem gives

$$
\frac{\partial V_{t+1}^{j+1}}{\partial a_{t+1}^{j+1}}=\left(1+\left(1-\tau^{k}\right) r_{t}\right) \frac{\nu}{\left(1+\tau^{c}\right) c_{t+1}^{j+1}}
$$

Substituting (24) and (25) into (22) yields

$$
\frac{\nu}{\left(1+\tau^{c}\right) c_{t}^{j}}=\left(1+\left(1-\tau^{k}\right) r_{t}\right) \beta \xi^{j+1} \frac{1}{\int_{\mathbb{R}^{+}} e^{-\psi^{j} V_{t+1}^{j+1}} v\left(d x_{t+1} \mid \eta_{t}^{j}\right)} \int_{\mathbb{R}^{+}} e^{-\psi^{j} V_{t+1}^{j+1}} \frac{\nu}{\left(1+\tau^{c}\right) c_{t+1}^{j+1}} v\left(d x_{t+1} \mid \eta_{t}^{j}\right)
$$

Combining (22) and (23) yields the intratemporal optimal condition between consumption and labour for $j=1, \ldots, J_{r}-1$ as

$$
c_{t}^{j}=\frac{\nu}{\left(1+\tau^{c}\right)(1-\nu)}\left(1-\tau_{t}^{l}-\mathbb{1}_{s} \tau^{s}\right) w_{t}^{j} h_{t}^{j}\left(1-l_{t}^{j}\right),
$$


By substituting (27) into the budget constraint, $l_{t}^{j}$ can be expressed as a function of $a_{t+1}^{j+1}$ as

$$
\begin{aligned}
l_{t}^{j}=l_{t}^{j}\left(a_{t+1}^{j+1}\right)= & \left(\nu+\frac{1-\nu}{\left(1-\tau_{t}^{l}-\mathbb{1}_{s} \tau^{s}\right) w_{t}^{j} h_{t}^{j}}\left((1+\mu) a_{t+1}^{j+1}-\right.\right. \\
& \left.\left.\left(1+\left(1-\tau^{k}\right) r_{t}\right) a_{t}^{j}+\left(1-\mathbb{1}_{s}\right) \tau^{s} y_{t}^{s}-q_{t}-\chi\right)\right) .
\end{aligned}
$$

Likewise, we can also express $c_{t}^{j}$ as

$$
\begin{aligned}
c_{t}^{j}=c_{t}^{j}\left(a_{t+1}^{j+1}\right)= & \frac{1}{\left(1+\tau^{c}\right)}\left(\left(1+\left(1-\tau^{k}\right) r_{t}\right) a_{t}^{j}+\left(1-\tau_{t}^{l}-\mathbb{1}_{s} \tau^{s}\right) w_{t} h_{t}^{j} l_{t}^{j}-\left(1-\mathbb{1}_{s}\right) \tau^{s} y_{t}^{s}+\right. \\
& \left.\chi+q_{t}-(1+\mu) a_{t+1}^{j+1}\right) .
\end{aligned}
$$

Equations (28) and (29) reduce the choice variables down to only $a_{t+1}^{j+1}$. Hence, we can then rewrite the optimality condition (26) as

$$
\begin{aligned}
& \frac{\nu}{\left(1+\tau^{c}\right) c_{t}^{j}\left(a_{t+1}^{j+1}\right)} \\
= & \left(1+\left(1-\tau^{k}\right) r_{t}\right) \beta \xi^{j+1} \frac{1}{\int_{\mathbb{R}^{+}} e^{-\psi^{j} V_{t+1}^{j+1}} v\left(d z_{t+1} \mid \eta_{t}^{j}\right)} \int_{\mathbb{R}^{+}} e^{-\psi^{j} V_{t+1}^{j+1}} \frac{\nu}{\left(1+\tau^{c}\right) c_{t+1}^{j+1}\left(a_{t+2}^{j+2}\right)} v\left(d x_{t+1} \mid \eta_{t}^{j}\right)
\end{aligned}
$$

Each household of every age $j$ at every time period $t$ choose policy functions $a_{t+1}^{j+1}\left(x_{t}\right)$, and corresponding policy functions $c_{t}^{j}\left(a_{t+1}^{j+1}\right)$ and $l_{t}^{j}\left(a_{t+1}^{j+1}\right)$ to solve the Euler equation (30).

\subsection{The Distribution of the Households}

Given the policy functions $c_{t}^{j}\left(a_{t+1}^{j+1}\right)$ and $l_{t}^{j}\left(a_{t+1}^{j+1}\right)$ that solve the optimality condition (30) under the states $\left\{x_{t}, X_{t} ; \Phi_{t}, \Psi_{t}\right\}$, the evolution of the distribution of households over age and time is jointly determined by the distribution of intrinsic productivity, the transition matrix of stochastic productivity, and the next-period saving policy function. Let $\phi\left(x_{t}\right)$ represent the distribution of household under individual state $x_{t}$. Since individuals are assumed to enter the economy at the age of 20 with no assets, their mass is solely distributed according to their intrinsic productivity and satisfies

$$
\int_{A \times \Theta \times H} d \phi\left(x_{t}=\{20, a, \theta, \eta, e, \kappa\}\right)=\int_{A \times \Theta \times H} d \phi\left(x_{t}=\{20,0, \theta, 0,0,0\}\right)=N_{t}^{20} .
$$

The distributions for cohorts above the age of 20 are determined by the policy function $a_{t+1}^{j+1}\left(x_{t}\right)$ and the transition probability $\pi\left(\eta^{\prime} \mid \eta\right)$ from the state $\eta$ in period $t$ to the state $\eta^{\prime}$ in period $t+1$.

$\phi\left(x_{t+1}=\left\{j+1, a_{t+1}^{j+1}\left(x_{t}\right), \theta^{\prime}, \eta^{\prime}, e^{\prime}, \kappa^{\prime}\right\}\right)=\int_{A \times \Theta \times H} a_{t+1}^{j+1}\left(x_{t}\right) \cdot d \phi\left(x_{t}=\{j, a, \theta, \eta, e, \kappa\}\right) \cdot \pi\left(\eta^{\prime} \mid \eta\right)$.

The integration is only over the states $a \in A, \theta \in \Theta$ and $\eta \in H$ as the age-earning profile, $e$, is exogenously given for age $j$ and the historical earnings, $\kappa$, is determined by the past states of the economy $\left\{x_{t}, X_{s} ; \Phi_{s}, \Psi_{s}\right\}_{s=t-j+20}^{t}$. 


\section{$2.5 \quad$ Firms}

The model assumes the representative firm that hires capital $K_{t}$ and labour $L_{t}$ to produce a single type of output with a constant returns to scale Cobb-Douglas production function $F\left(K_{t}, L_{t}\right)=\Omega_{t} K_{t}^{\alpha} L_{t}^{1-\alpha}$ where $\Omega_{t}$ is a total factor productivity and $\alpha$ and $1-\alpha$ are the output elasticity of capital and labour respectively. The law of motion for capital is characterized by

$$
\left(1+n_{t}\right)(1+\mu) K_{t+1}=(1-\delta) K_{t}+I_{t},
$$

where capital depreciates at a fixed rate $\delta$ and $I_{t}$ is the amount of investment in the period $t$.

The firm maximizes its profit by choosing $K_{t}$ and $L_{t}$, while taking an interest rate $r_{t}$ and a wage rate $w_{t}$ as given. The firms' profit maximization problem is

$$
\max _{\left\{K_{t}, L_{t}\right\}} \Omega_{t} K_{t}^{\alpha} L_{t}^{1-\alpha}-\left(r_{t}+\delta\right) K_{t}-w_{t} L_{t},
$$

and the profit maximizing conditions are

$$
\begin{aligned}
& (1-\alpha) \Omega_{t}\left(\frac{K_{t}}{L_{t}}\right)^{\alpha}=w_{t}, \\
& \alpha \Omega_{t}\left(\frac{L_{t}}{K_{t}}\right)^{1-\alpha}=r_{t}+\delta
\end{aligned}
$$

The factor market clearing condition requires $K_{t}=\tilde{K}_{t}$ and $L_{t}=\tilde{L}_{t}$, where $\tilde{K}_{t}$ and $\tilde{L}_{t}$ are supplies of capital and labour.

\subsection{Government}

The government maintains two separate balanced budgets: one for the general government spending and another for the pension system.

For the general government spending, the model assumes that the government spends an exogenous amount as a constant share of GDP and repays debt with interest rate $\left(1+r_{t}\right) D_{t}$. On the revenue side, the government raises tax from labour income, capital income, and consumption. Also, it issues new debt $D_{t+1}$ which grows at population growth rate $n_{t}$ and labour augmenting productivity growth rate $\mu$. The payroll tax rate is endogenously determined so that the general government budget is balanced

$$
\begin{aligned}
G_{t}+\left(1+r_{t}\right) D_{t}= & \sum_{j=1}^{J} \int_{A \times \Theta \times H}\left[\tau^{l} w_{t} h^{j} l_{t}^{j}+\tau^{k} r_{t} a_{t}(x)+\tau^{c} c(x)\right] \phi(x) \cdot m_{t}^{j} \\
& +\left(1+n_{t}\right)(1+\mu) D_{t+1} .
\end{aligned}
$$

On the pension system, the government sets the payroll tax rate so that the total payroll tax revenue collected matches the total social security benefits spending in each period

$$
\sum_{j=1}^{J} \int_{A \times \Theta \times H} \chi \phi(x) \cdot m_{t}^{j}=\sum_{j=1}^{J} \int_{A \times \Theta \times H} \tau^{s} \min \left\{w_{t} h^{j} l_{t}^{j}, y_{t}^{s}\right\} \phi(x) \cdot m_{t}^{j} .
$$

The government is also assumed to uniformly redistribute accidental bequests which equal the end-period wealth of the deceased individuals to all living individuals. 


\subsection{Equilibrium conditions}

With an assumption of perfect foresight in the intertemporal dynamic OLG model, for the set of aggregate state of the economy $X_{t}=\left\{\phi_{t}\left(x_{t}\right)\right\}$, government policy schedule $\Psi_{t}=\left\{G_{t}, D_{t}, \chi, \tau_{t}^{s}, \tau_{t}^{k}, \tau_{t}^{l}, \tau_{t}^{c}, y_{t}^{s}\right\}$, and population projection $\Phi_{t}=\left\{\left(N_{t}^{j}\right)_{j=1}^{J},\left(f_{t}^{j}\right)_{j=1}^{J},\left(\xi_{t}^{j}\right)_{j=1}^{J}\right\}$, the recursive competitive equilibrium consists of households' policy functions $\left\{a_{t+1}^{t+1}\left(x_{t}\right), c_{t}^{j}\left(a_{t+1}^{t+1}\left(x_{t}\right)\right), l_{t}^{j}\left(a_{t+1}^{t+1}\left(x_{t}\right)\right)\right\}_{t=0}^{T}$ for each individual state $x_{t}=\{j, a, \theta, \eta, e, \kappa\}$, factor prices $\left\{w_{t}, r_{t}\right\}_{t=0}^{T}$, and accidental bequest $q_{t}$ that satisfy the following conditions:

1. Aggregate and individual variables are consistent with the distribution of agents over individual states $\phi_{t}\left(x_{t}\right)$ that evolves according to policy rules.

2. Households' policy functions solve the Bellman equation (14).

3. Firm factor input choices $K_{t}, L_{t}$ solve firm's profit optimization (34).

4. The labor income tax and social security tax satisfies the government's budget balances (37) and (38).

5. Accidental bequests are allocated according to

$$
q_{t} \sum_{j=1}^{J} \int_{A \times \Theta \times H} d \phi_{t}(x) \cdot m_{t}^{j}=\sum_{j=1}^{J} \int_{A \times \Theta \times H}\left(1-\xi_{t+1}^{j+1}\right)(1+\mu) a_{t+1}^{j+1}\left(x, X_{t} ; \Psi_{t}, \Phi_{t}\right) d \phi_{t}(x) \cdot m_{t}^{j} .
$$

6. All markets clear

- Factor market for labour:

$$
L_{t}=\tilde{L}_{t}
$$

- Factor market for capital:

$$
K_{t}=\tilde{K}_{t}, \tilde{K}_{t}+B_{t}=A_{t}
$$

- Good market:

$$
Y_{t}=C_{t}+\left(\left(1+n_{t+1}\right)(1+\mu) \tilde{K}_{t+1}-(1-\delta) \tilde{K}_{t}\right)
$$

7. The economy is in the stationary state where $\left\{X_{s+1}=X_{s}, \Psi_{s+1}=\Psi_{s}, \Phi_{s+1}=\right.$ $\left.\Phi_{s}\right\}_{s=t}^{\infty}$

\section{Calibration}

This section explains the calibration strategy and the parameterization of the model. The country considered is the United States and one period in the model corresponds to one year.

To address the point that the current year population distribution is not stationary, I follow the general calibration strategy form Nishiyama (2015) by start solving for the equilibrium with the actual population distribution in 1975 where people are assumed 
Table 1: Parameter summary

\begin{tabular}{|c|c|c|c|}
\hline Parameter & & Value & Source/comment \\
\hline \multicolumn{4}{|l|}{ Demographics } \\
\hline Survival probabilities & $\xi_{t}^{j}$ & see text & Social Security Administration \\
\hline Fertility rates & $f_{t}^{j}$ & see text & The United Nations \\
\hline Maximum age & $J$ & 100 & \\
\hline Retirement age & $J_{R}$ & 67 & Eligible for medicare \\
\hline Labour augmenting prod. growth & $\mu$ & $1.5 \%$ & Average growth rate of per-capita real GDP \\
\hline \multicolumn{4}{|l|}{ Preference } \\
\hline Discount factor & $\beta$ & 0.9875 & Target: capital-output ratio of 3.0 \\
\hline Taste parameter of consumption & $\nu$ & 0.375 & Target: actual working time (OECD) \\
\hline \multicolumn{4}{|l|}{ Age dependent risk aversion } \\
\hline Risk parameter in future utility & $\psi$ & see text & Calculated from Albert and Duffy (2012) \\
\hline \multicolumn{4}{|l|}{ Labour productivity } \\
\hline Age earning profile & $e^{j}$ & see text & Follows G. D. Hansen (1993) \\
\hline Intrinsic productivity (education) & $\theta$ & see text & U.S. Bureau of Labour Statistics (BLS) \\
\hline stochastic productivity & $\eta^{j}$ & & \\
\hline - autocorrelation & $\rho$ & 0.93 & Target: the variance of log labour earning \\
\hline - variance & $\sigma_{\epsilon}^{2}$ & 0.027 & Target: the variance of log labour earning \\
\hline \multicolumn{4}{|l|}{ Production and technology } \\
\hline Income share & $\alpha$ & 0.41 & U.S. Bureau of Labour Statistics (BLS) \\
\hline Total factor productivity & $\Omega$ & 0.875 & Target: wage $=1.0$ in 2018 \\
\hline Depreciation rate & $\delta$ & $9.7 \%$ & Target: interest rate $=5.0 \%$ in 2018 \\
\hline \multicolumn{4}{|l|}{ Government } \\
\hline Maximum taxable income & $y^{s}$ & $\$ 128,400$ & Social Security Administration \\
\hline Social security benefit & $\chi$ & see text & Social Security Administration \\
\hline Government spending & $\mathrm{G}$ & $20 \%$ of GDP & Average rate $1975-2018$ \\
\hline Government debt & $\mathrm{D}$ & $60 \%$ of GDP & \\
\hline Consumption tax rate & $\tau^{c}$ & $5.54 \%$ & Nation average of retail sales taxes \\
\hline Capital tax rate & $\tau^{k}$ & $15 \%$ & Capital gains tax rate (median bracket) \\
\hline
\end{tabular}

to believe that they were in equilibrium before they realize the population transition in the following year. The model shows the equilibrium transition path between 1975 and $2200^{3}$. A set of preferences and policy parameters are calibrated so that the model-generated 2018 economy matches certain objectives of the actual United States economy in the same year as summarized in table $1^{4}$.

\subsection{Demographics}

The dynamics of demographic structure are determined by exogenous assumptions of survival probabilities and fertility rates. Age- and time-dependent survival probabilities from 1975 to 2095, data from 1975-2018 being the actual historical data, are from the SSA's intermediate population projection from the 2020 Trustee's report. Since the survival probabilities are in the 5-year interval, annual values are linearly interpolated across both age and time. Figure 1 shows unconditional survival rates of each age group in the year 2018 and 2100.

\footnotetext{
3 The model solves for a solution well beyond 2200 due to interactions in population dynamics that yield a slow convergence

${ }^{4}$ The parameters are calibrated separately for the model with constant and age-dependent risk aversion assumptions to match certain objectives. However, the calibrated parameter values under both assumptions turn out to be similar and therefore only one value for each parameter is shown.
} 


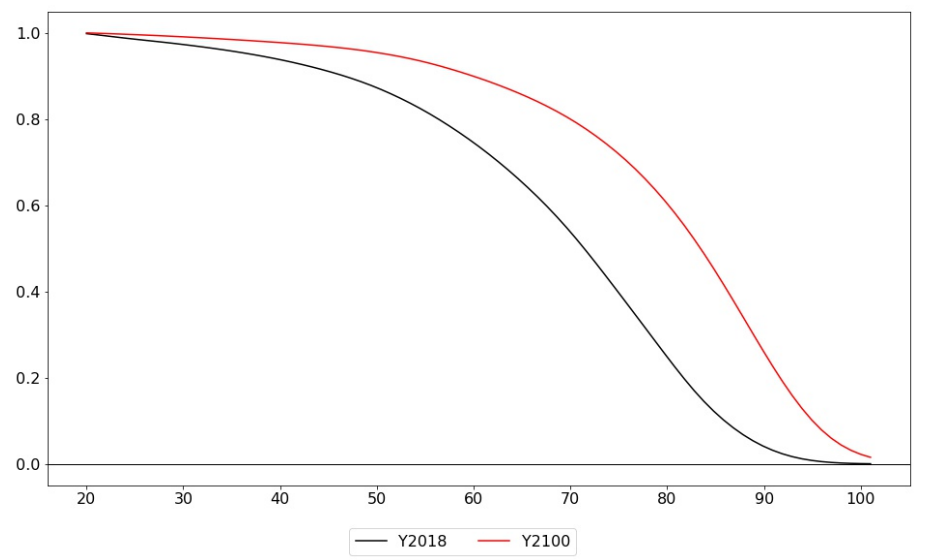

Figure 1: Unconditional survival rates

The rate of new entrants in 1975 was calibrated to match the actual old-age dependency ratio of $19.7 \%$. The data from 1976 to 2018 are actual historical data whereas the data between 2020-2100 are median value forecast from the United Nations. Since the data is provided on the basis of 5-year interval, annual fertility rates of different age cohorts are linearly interpolated. Cohorts age 0-19 are assumed to survive to the next period with a probability of one. As a result, the amount of new entrants to the economy in each period can be estimated according to age-specific fertility rates and amount of fertile cohorts 20 years ago as

$$
\begin{aligned}
N_{t}^{20} & =\left(f_{t-20}^{15-16} \sum_{j=15}^{19} N_{t-20}^{j}+f_{t-20}^{20-24} \sum_{j=20}^{24} N_{t-20}^{j}+f_{t-20}^{25-29} \sum_{j=25}^{29} N_{t-20}^{j}+f_{t-20}^{30-34} \sum_{j=30}^{34} N_{t-20}^{j}\right. \\
& \left.+f_{t-20}^{35-39} \sum_{j=35}^{39} N_{t-20}^{j}+f_{t-20}^{40-44} \sum_{j=40}^{44} N_{t-20}^{j}+f_{t-20}^{45-49} \sum_{j=45}^{49} N_{t-20}^{j}\right) .
\end{aligned}
$$

Females are assumed to account for $50 \%$ of the total population which closely matches the empirical data. To forecast population dynamics after the year 2100 , survival rates are assumed to be the same as that of 2095 and fertility rates as that of 2100 .

Figure 2 shows the model-generated population structure of the benchmark year and of the year 2100, the former closely resembles the actual population.

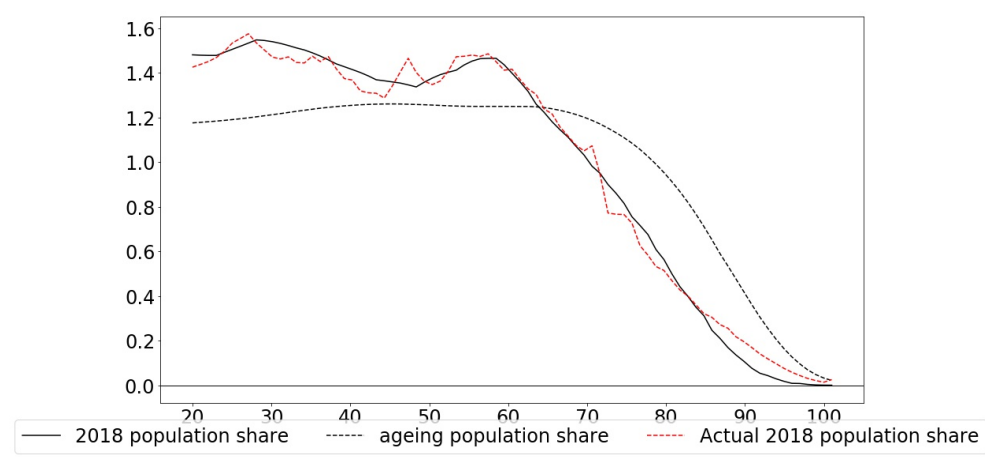

Figure 2: Demographic structure 
Figure 3a gives the old-age dependency ratio of cohorts older than 65 to working cohorts between 20-65. The value in 2018 is at $25.5 \%$ which is close to the actual ratio of $24.14 \%$. This gradually increases to $45.5 \%$ in the year 2100 . The share of working-age cohorts to cohorts aged 20-100 decreases from 82.5\% in the year 2018 to $71.7 \%$ in the year 2100 .

The labour-augmenting productivity is assumed to grow at the average growth rate of the real GDP per capita between 1990-2015 which is $1.5 \%$ per year.

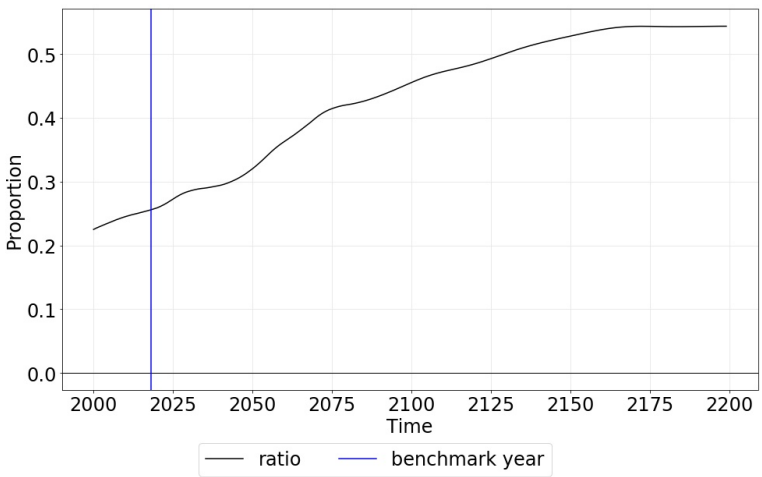

(a) Old-age dependency ratio

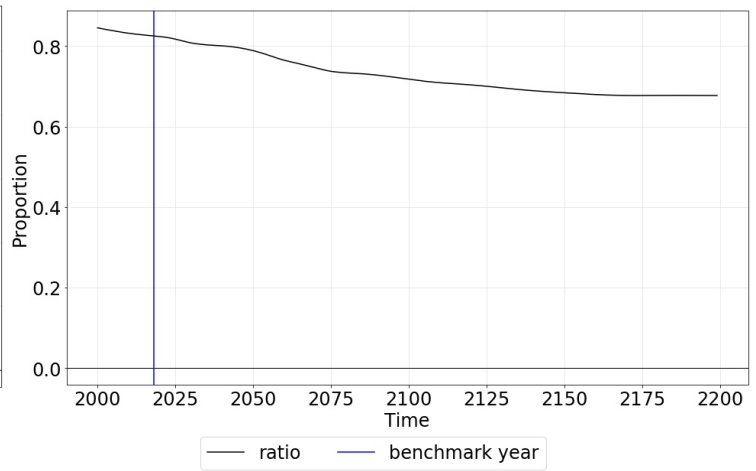

(b) Ratio of working-population

Figure 3: Population dynamics

\subsection{Preferences}

The discount rate, $\beta$, is calibrated to be 0.9875 to match the empirical capital-output ratio of 3.0 in the benchmark year 2018 and the taste parameter of consumption, $\nu$, is 0.375 so that working individuals spend $33 \%$ of their disposable time on work as suggested in the OECD data ${ }^{5}$.

\subsection{Age-dependent risk aversion in future utilities}

This paper considers two risk aversion assumptions: one with a constant risk aversion and another with an age-dependent risk aversion.

Estimating relative risk aversion in Epstein-Zin recursive preferences is challenging because the parameters are functions of the discounted future unobservable consumption (and leisure) plan (Chen et al., 2013) ${ }^{67}$ and the presence of endogenous human capital also requires risk aversion to incorporate the fact that labour helps absorb

\footnotetext{
${ }^{5}$ Average annual hours of the US workers in 2018 is 1783 hours (OECD). The calculation assumes that the total time available is 5,475 hours ( 15 hours per day, 365 days per year)

6 This is unlike the case where household preferences are assumed to follow a HARA-class utility function and prices of $n$ risky assets are assumed to be log-normally distributed with the stochastic process following a time homogenous Markov process. In such a case, one can derive the analytical relationship between Pratt (1964) and Arrow (1965)s relative risk aversion and portfolio choice decisions.

7 L. P. Hansen et al. (2008) presents an analytical solution to the value of relative risk aversion under a specific case of unit elasticity of intertemporal substitution where consumption follows a log-linear vector time series process. However, the elicitation process is still challenging due to the availability issue of time series of age-dependent consumption and the presence of endogenous labour supply.
} 
shocks (Swanson, 2018). The elicitation strategy in this paper is, therefore, to directly estimate risk aversion parameter $\psi^{j}$ from the certainty equivalent of next period value function. To do this, this paper considers the results from experimental economics of a widely-used lottery choice menu proposed by Holt and Laury (2002) which can be used to estimate the degree of risk aversion ${ }^{8}$. In such experiment, participants make 10 decisions, each consists of choosing between paired lottery choices: one with low variance (option A) and another with high variance (option B). Lottery A gives payoffs of either $\$ 16.00$ or $\$ 20.00$ and lottery B gives either $\$ 1.00$ or $\$ 38.50$. The probability of earning high payoff in each lottery choice increases from 0.1 to 1.0 in 0.10 increments in each decision. The higher tendency of choosing a safe lottery choice when the chance of getting high payoff is low indicates increasing risk aversion.

To elicit risk aversion of young and old adults, this study refers to the work by Albert and Duffy (2012), which applied Holt and Laury's lottery choice to two age groups, and further makes 2 assumptions. First, individual's preferences towards the next period value function behave in the same manner as towards monetary payoffs from the paired lottery experiment. Second, certainty equivalence of experiment participants follows

$$
\frac{1}{\psi} \ln \mathbb{E}_{t}\left(e^{-\psi V^{+}}\right)
$$

The cut-off values of risk aversion can be calculated to characterize participants who switch from option A to B under certain decisions (Table 2).

Table 2: Paired lottery experiment

\begin{tabular}{ccccc}
\hline Decision & Prob. of high payoff & Choose option B if & \multicolumn{2}{c}{ Proportion } \\
& & & Young & Old \\
\hline 1 & $1 / 10$ & $\psi<-0.063$ & 0.000 & 0.000 \\
2 & $2 / 10$ & $-0.063<\psi<-0.0158$ & 0.110 & 0.030 \\
3 & $3 / 10$ & $-0.0158<\psi<0.0174$ & 0.000 & 0.050 \\
4 & $4 / 10$ & $0.0174<\psi<0.0460$ & 0.050 & 0.010 \\
5 & $5 / 10$ & $0.0460<\psi<0.0735$ & 0.120 & 0.070 \\
6 & $6 / 10$ & $0.0735<\psi<0.1022$ & 0.220 & 0.070 \\
7 & $7 / 10$ & $0.1022<\psi<0.1350$ & 0.200 & 0.090 \\
8 & $8 / 10$ & $0.1350<\psi<0.1772$ & 0.110 & 0.040 \\
9 & $9 / 10$ & $0.1772<\psi<0.2448$ & 0.110 & 0.160 \\
10 & $10 / 10$ & $\psi>0.2448$ & 0.080 & 0.480 \\
\hline
\end{tabular}

In decision group 10, I assume the probability of high payoff to be 0.99 instead of 1.0 to be able to calculate corresponding $\psi$ value. This results in corresponding range $0.2448<\psi<0.4658$.

The values of risk aversion parameter of young and old adults can then be calculated by using the proportion of safe choices in each of the 10 decisions together with the value of corresponding cut-off points ${ }^{9}$. With this method, the value of risk

\footnotetext{
${ }^{8}$ In their study, Holt and Laury (2002) estimate risk aversion with CRRA utility function and a hybrid power-expo utility function.

9 The median values between cut-off points are used in the calculation. For example, $(-0.063-$ $0.0158) / 2=-0.039$ is used for individual who choose safe lottery in the first decision but choose a risky lottery in the second decision.
} 
aversion is 0.116 for adults aged 32 and 0.231 for adults aged 71 . The remaining values are interpolated by assuming a linear relationship with age. Under a constant risk aversion assumption, the value is 0.164 , a weighted average of age-dependent risk aversion and the share of cohorts in the benchmark year. Values of risk aversion in future utility under the the two scenarios are illustrated in Figure 4.

To make sure that these values fall into a reasonable range, they can be converted back into relative risk aversion, $\gamma$, according to the relationship $\psi^{j}=-(1-\beta)\left(1-\gamma^{j}\right)$ which gives the value in the range of 9-32., in line with the values suggested by the literature (e.g., Chen et al. (2013)'s empirical estimations ranges from 17-60).

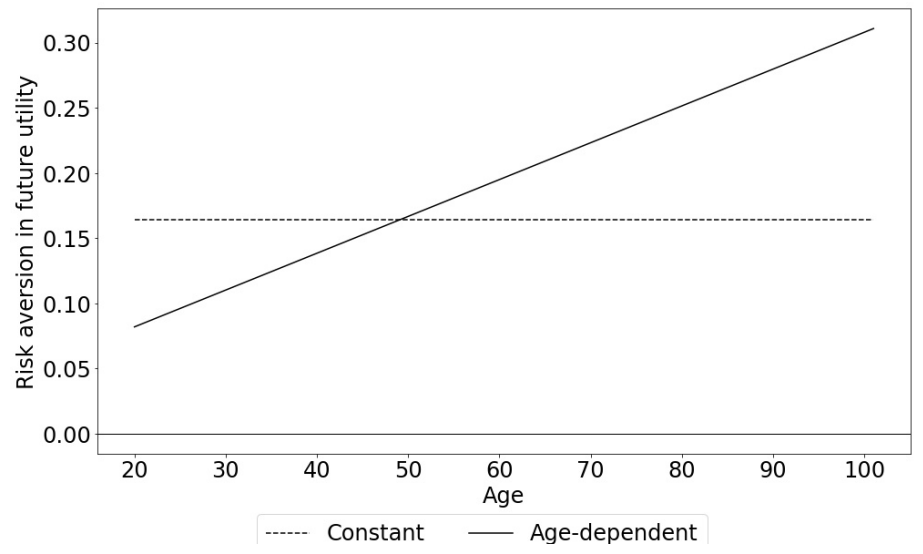

Figure 4: The values of risk aversion under the two scenarios

\subsection{Productivity}

The income share of capital in the Cobb-Douglass production function is 0.41 , calculated as 1 minus the 2000-2016 average value of labour income share from BLS (Giandrea and Sprague, 2017). The depreciation rate is $9.7 \%$ so that the interest rate in the benchmark year is around $4 \%$ and the total factor productivity is calibrated to be 0.875 to normalize the wage rate to 1.0 in the benchmark year.

Labour productivity is jointly determined by 3 components: age-earning profile, education level, and idiosyncratic productivity. The age-earning profile, $e^{j}$, of working cohorts follows G. D. Hansen (1993). The estimates are linearly interpolated to cover the cohorts from the age of 20-80 and the age-earning of the 20-year-old cohort is normalized to 1.0. This deterministic age earning profile is assumed to be constant across time.

Individuals also differ in their education levels which can be categorized into 3 groups: high school graduate or less, some college or associate degree, bachelor's degree and higher. Median hourly earnings and the number of workers of each education level are obtained from the BLS and the weighted average productivity across education types is normalized to 1.0 for an individual aged 20 .

Log of labour earnings is represented by $\ln \left(w_{t} h^{j} l_{t}^{j}\right)=\ln \left(w_{t}\right)+\ln \left(e^{j}\right)+\theta+\eta^{j}+\ln \left(l_{t}^{j}\right)$. Therefore, the variance of log labour earnings at age $j$ is

$$
\begin{aligned}
\operatorname{Var}\left[\ln \left(w_{t} h^{j} l^{j}\right)\right] & =\operatorname{Var}[\theta]+\operatorname{Var}\left[\eta^{j}\right]+\operatorname{Var}\left[\ln \left(l_{t}^{j}\right)\right] \\
& +2 \cdot \operatorname{Cov}\left[\theta, \ln \left(l_{t}^{j}\right)\right]+2 \cdot \operatorname{Cov}\left[\eta^{j}, \ln \left(l_{t}^{j}\right)\right]
\end{aligned}
$$


For the purpose of calibrating the model's parameter, the focus is on the first two components of the variance which can be explicitly written as

$$
\operatorname{Var}\left[\ln \left(w_{t} h^{j} l^{j}\right)\right]=\sigma_{\theta}^{2}+\sigma_{\epsilon}^{2} \sum_{i=1}^{j} \rho^{2(i-1)}
$$

Since the variance of fixed effect, $\sigma_{\theta}^{2}$, is given by the empirical data of earnings by education level, only the variance $\sigma_{\epsilon}^{2}$ is calibrated to target the variance of log labour earning of 0.3 at the age of 25 and 0.9 at the age of 60 according to the empirical study by Storesletten et al. (2004). This requires $\sigma_{\epsilon}^{2}$ of 0.027 and autocorrelation, $\rho$, of 0.93. The Rouwenhorst method is used to discretize a Markov process of a finite number $n_{\eta}$ of shocks. Since the shock is idiosyncratic and complies with the law of large number, the model is absent of aggregate shock.

\subsection{Government}

The government operates a pay-as-you-go pension system where the social security benefit is computed using AIME which summarizes up to 35 years of workers indexed earnings. Following Kitao (2014) and French (2005), the social security benefits or the primary insurance amount (PIA) is calculated using a concave piecewise linear function of AIME given by

$$
\begin{aligned}
\kappa_{t+1} & = \begin{cases}\kappa_{t}+\frac{y_{L, t}}{35} & \text { for } 20 \leq j \leq 55 \\
\kappa_{t}+\max \left\{0, \frac{y_{L, t}-e_{t}}{35}\right\} & \text { for } 55<j \leq J_{R}\end{cases} \\
y_{L, t} & =\min \left\{w_{t} h^{j} l_{t}^{j}, y_{t}^{s}\right\}
\end{aligned}
$$

The PIA is then computed from AIME as the sum of three separate percentages of a portion of annual AIME according to the SSA's 2018 formula: $90 \%$ of the first $\$ 10,740,32 \%$ for AIME over $\$ 10,740$ through $\$ 64,764$, and $15 \%$ of AIME over $\$ 64,764$. This can be written as

$\chi=P I A_{t}= \begin{cases}0.9 \times A I M E_{t} & \text { if } A I M E_{t} \leq \$ 10,740 \\ \$ 9,666+0.32 \times\left(A I M E_{t}-\$ 10,740\right) & \text { if } \$ 10,740<A I M E_{t} \leq \$ 64,764 \\ \$ 26,954+0.15 \times\left(A I M E_{t}-\$ 64,764\right) & \text { if } \$ 64,764<A I M E_{t}\end{cases}$

With this approach, an individual pays tax up to the maximum taxable earnings, $y_{t}^{s}$, which equals $\$ 128,400$ in the year 2018 , and receives the same social security benefits from retirement until deceased. The year 2018 average wage equals $\$ 52,145.80$ which serves as the unit in the model. The maximum taxable earnings are assumed to increase by about $1 \%$ per year until the year 2100 , in line with the historical trend. However, this approach still simplifies the social security benefits because it assumes that individuals, regardless of their earning history, who retire in the same year will receive the same benefit amount. An alternative assumption with social security benefit distribution is considered in the Section A.3. 
The government spending is assumed to be constant at $20 \%$ of the output which is an average rate from 1975 to 2018 . The debt to GDP ratio is assumed to be maintained at $60 \%$ of GDP. The model also assumes a fixed consumption tax rate of $5.54 \%$, the US simple average of retail sales taxes across different states in 2018, and a fixed capital tax rate of $15 \%$, the median bracket of the long-term capital gains tax rate.

\section{Numerical Results}

This section consists of 4 parts. The first part examines household life-cycle decisions of the 2018 benchmark economy. This will serve as a reference for comparison with outcomes under alternative fiscal policies in the year 2100 in the second part. The third part will then examine transition paths of per-capita variables, starting from the benchmark year towards new long-run equilibria. Lastly, the welfare impacts under different fiscal reforms which will be thoroughly analysed.

In each part, two types of household preferences will be contrasted: one with constant risk aversion and another with age-dependent increasing risk aversion. The analysis will elaborate on why risk aversion assumption is crucial and how having increasingly risk-averse individuals may lead policymakers to favour one reform over another.

\subsection{Benchmark Economy}

The year 2018 is assumed to be the benchmark year, when the demographic structure closely resembles that of the actual US economy and other economic targets are matched as explained in Section 3. As in Nishiyama (2015), the economy in the benchmark year is not stationary but a transition from the pseudo stationary state in 1975 towards the long-run equilibrium.

Figure 5a shows the life-cycle labour supply, taken together the decisions about whether to participate in the labour force and how many hours to work. The black line shows values under constant risk aversion and the red shows those under agedependent risk aversion, with the percentage deviation between the two represented by the blue area. Labour supply initially increases due to a rapid increase in working productivity until around the age of 30 . Afterwards, it starts to decline due to different effects: wealth accumulation, a growing impatience of older households which causes them to prefer instantaneous utility from leisure, and declining labour productivity. With an age-dependent assumption, young individuals tend to work slightly more to accumulate precautionary savings and reduce earning risk they will have to face when they get older.

Figure 5b shows a hump-shaped profile of life-cycle asset holdings by individuals of different age cohorts which can be explained by two main motives. On the one hand, life-cycle saving motives cause working individuals to save up to finance consumption after retirement. On the other hand, precautionary saving motives aim to safeguard against future idiosyncratic income uncertainties. The latter motives are more pronounced under the age-dependent risk aversion because people put more emphasis on lowering the randomness of their future utilities, causing them to save slightly more when they are young. 
Consumption increases towards retirement along with rising working income and accumulated wealth. As mortality risk rises, particularly sharply after retirement, people will start to prioritize early consumption which helps explain the gradual decline. With an age-dependent increasing risk aversion, higher earnings from more labour supply and savings allow working-age individuals to consume slightly more. As can be seen in the graph, nevertheless, the differences in all life-cycle variables under the two risk aversion assumptions are not significant.

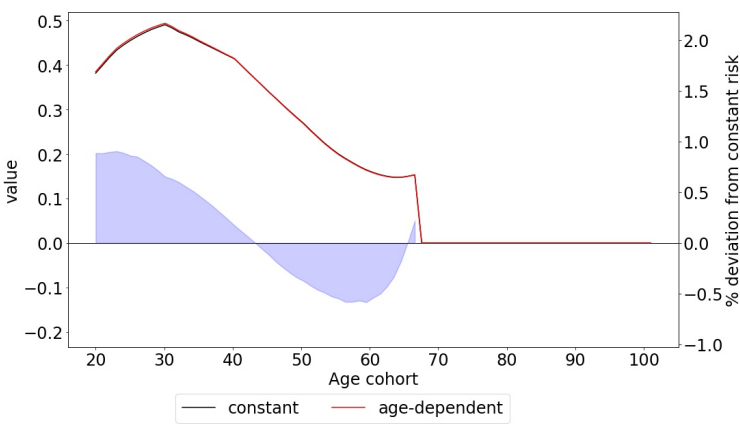

(a) Labour supply

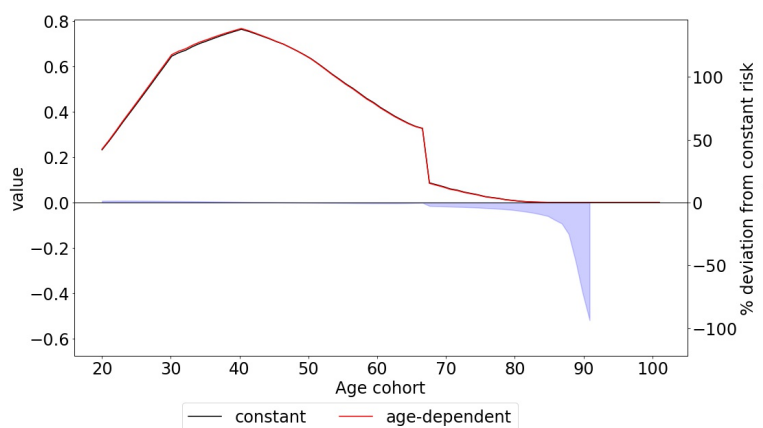

(c) Income

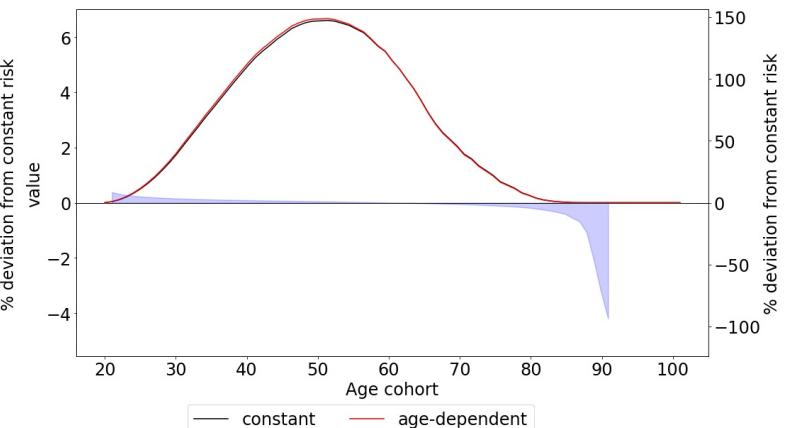

(b) Assets

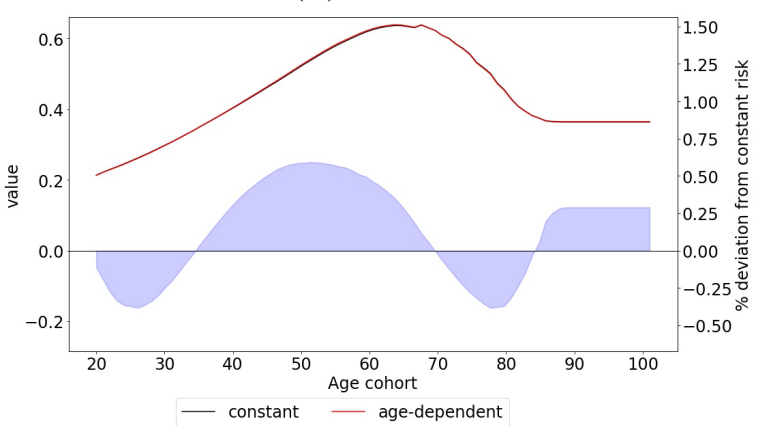

(d) Consumption

Figure 5: Life-cycle profile: Benchmark Economy

\subsection{Long-run effects}

This section evaluates the long-run ${ }^{10}$ life-cycle impacts of different policy alternatives commonly available to the government for dealing with population ageing. As mentioned in the calibration section, one population projection, in which the aggregate population gradually age due to lower mortality and birth rates, is considered. All individuals are assumed to follow the same historical economic and policy path from 1975 to 2018. The policy shock comes as a surprise and takes effect in the year 2019, after which everyone is assumed to adjust their expectation and behaviour with perfect foresight. The analysis compares the life-cycle behaviour in the benchmark year and in the year 2100 when the economy is expected to experience a dramatic increase in the share of old cohorts.

Without fiscal reform, the government budget is not sustainable under projected population ageing. Three alternative fiscal policies, adapted from that of Kitao (2014)

\footnotetext{
10 Since the model takes a very long time to converge, I pick the year 2100 as a proxy albeit not yet reach the long-run equilibrium.
} 
and Nishiyama (2015), are studied to finance the fiscal gap. In each scenario, only one policy variable is adjusted to balance the government budget while keeping everything else constant at the value in the benchmark year, including the payroll tax rate, the retirement age as well as the social security benefit function. Across all scenarios, the government spending is assumed to remain at $20 \%$ of GDP and debt level at $60 \%$ of GDP. The first option assumes that the government proportionally increases payroll tax rate. The second option linearly scales down the social security benefit. The third policy option extends the retirement age to increase payroll tax revenue suffice for the increase in social security benefits payment.

\subsubsection{Option 1: Increasing the payroll tax rate}

To balance the social security budget after the demographic change, the payroll tax has to increase by around $10 \%$ from $11 \%$ in the year 2018 to $21 \%$ by the year 2100 to support the increase in social security benefit spending paid to the increasing size of the elderly population. Labour income tax also needs to slightly increase by $0.5 \%$ to compensate for the decrease in government income levied from consumption and asset taxes.

Figure 6a compares the labour supply decision under the first policy option to that of the benchmark economy. By the year 2100, young households supply more labour to finance increasing post-retirement consumption due to an increase in life expectancy. This requires households to supply $4.4 \%$ more labour during their working age. Nevertheless, disposable income becomes lower by the year 2100 because higher tax rates reduce the available resources for consumption and saving. Overall, total consumption over the life cycle falls by about $5.5 \%$.

Regarding the life-cycle asset profiles, the younger population save less whereas the older save more. In addition to diminishing disposable income, the reallocation of asset is influenced by an increase in capital intensity since there are more middle- and old-age cohorts who have high savings and less young cohorts who supply more labour. The resulting lower interest rate discourages individuals to save. At the same time, however, longer life expectancy requires higher savings, especially among the older population, to support post-retirement spending. Similar to the benchmark economy, higher precautionary saving motives under the age-dependent increasing risk aversion scenario explains the higher life-cycle asset allocation compared to the constant case. 


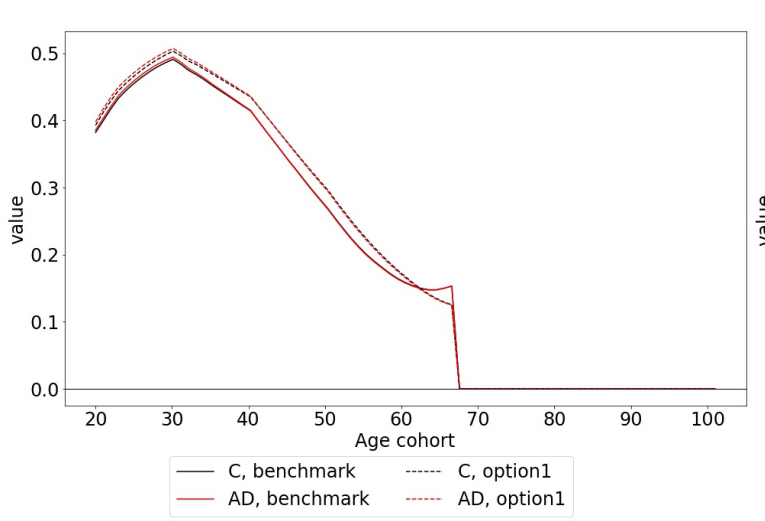

(a) Labour supply

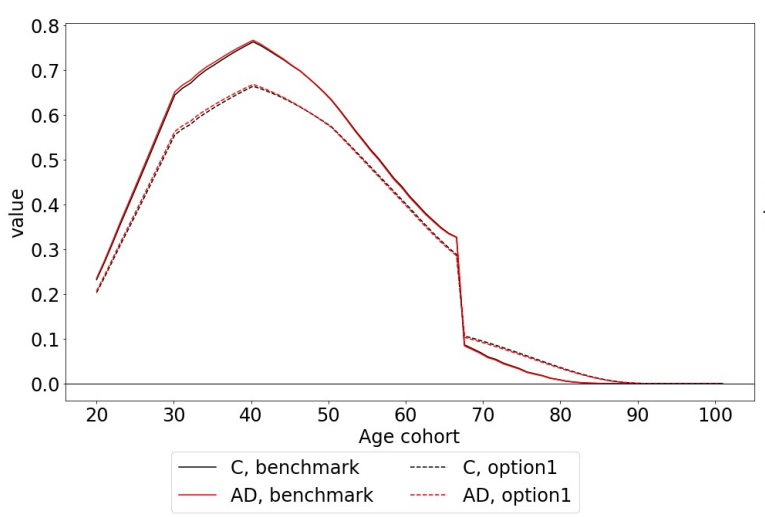

(c) Income

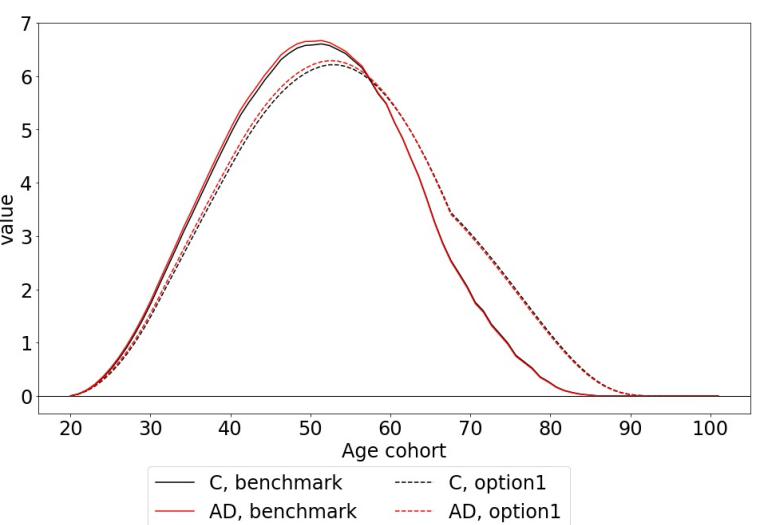

(b) Assets

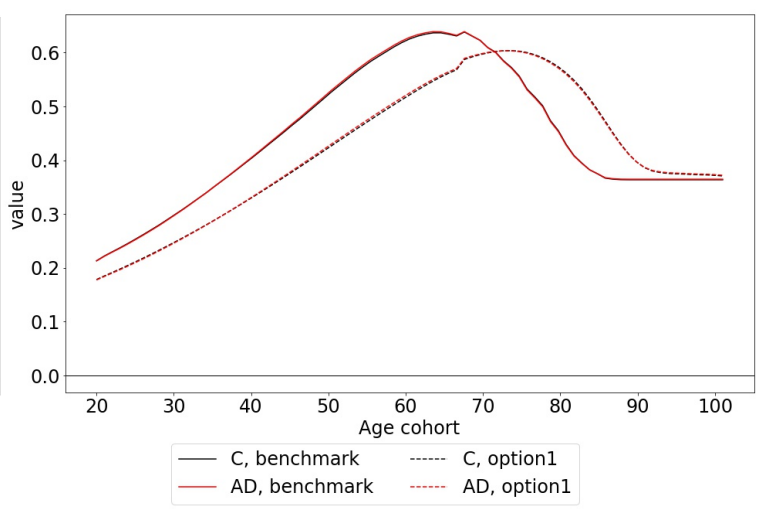

(d) Consumption

Figure 6: Life-cycle profile: Option 1

\subsubsection{Option 2: Cutting social security benefits}

In option 2, the government proportionally scales down the social security benefits calculated from AIME formula, which reaches about $42 \%$ by the year 2100. Expecting lower social security benefits, individuals become more self-dependent for their retirement spending and, therefore, increase their work effort to accumulate savings. Given a simplified assumption of constant retirement age, figure 7 a shows a significant increase in labour supply, specifically by a total of $12 \%$ over the lifetime, a much greater extent compared to option 1. Since the social security tax rate is constant, disposable income increases along with the increase in working hours.

Higher savings, especially right before retirement age, are required to compensate for the expected reduced benefits, resulting in a total $25.5 \%$ increase in assets throughout the life cycle. The more aggressive increase in savings compared to labour supply deepens the capital intensity and leads to significant changes in interest and wage rates.

On the demand side, reducing social security benefits lowers available resources and consumption among the very old cohorts compared to the benchmark. The profile of life-cycle consumption becomes smoother due to a lower interest rate that reduces the trade-off between immediate and future consumption. This smoother consumption profile is favourable for welfare improvement, as will be discussed in Section 4.4. 


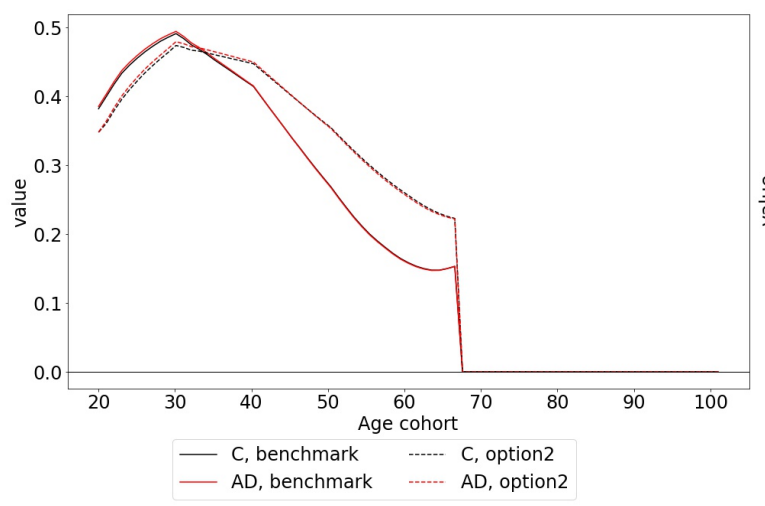

(a) Labour supply

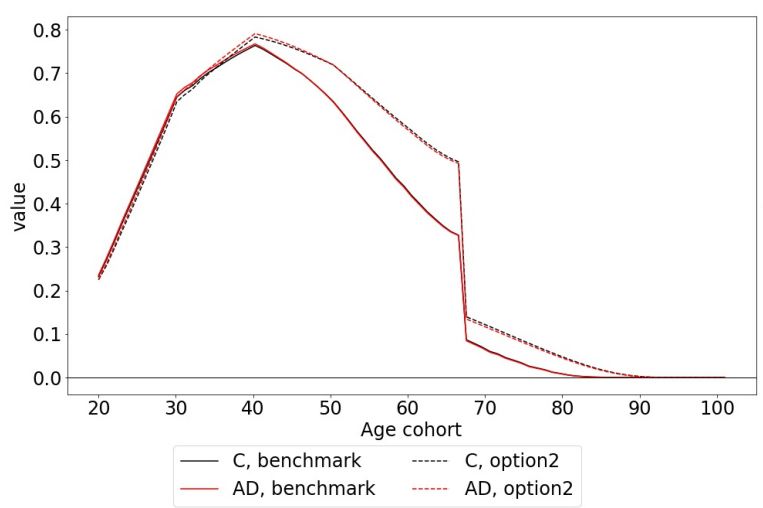

(c) Income

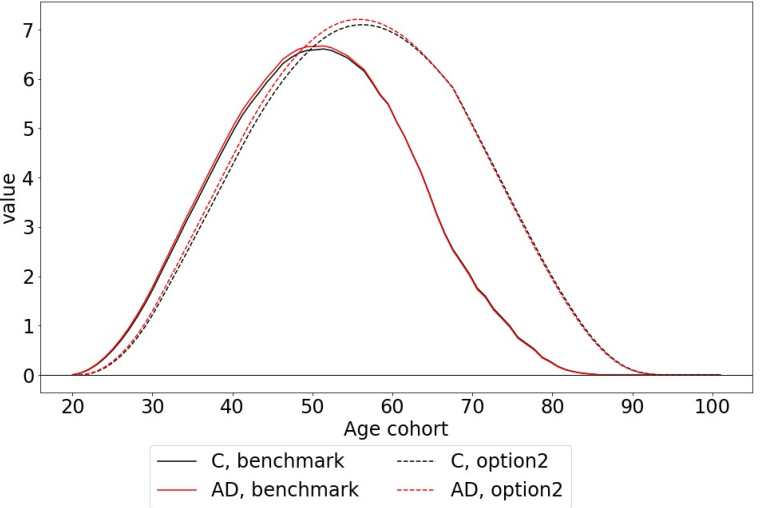

(b) Assets

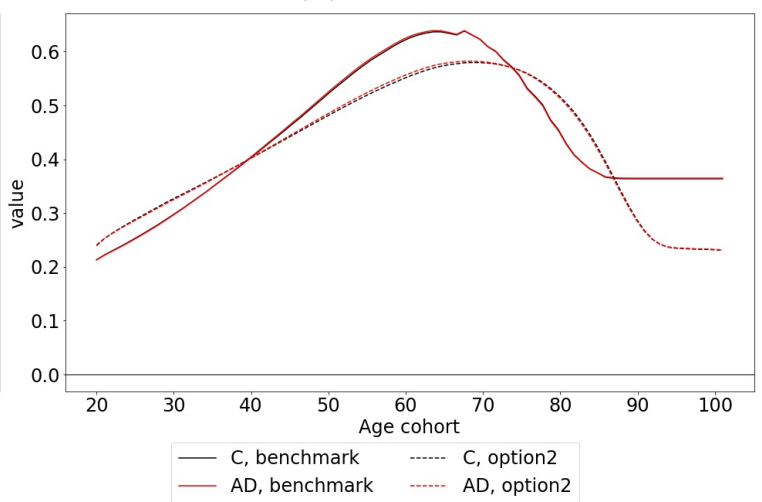

(d) Consumption

Figure 7: Life-cycle profile: Option 2

\subsubsection{Option 3: Extending the retirement age}

Under option 3, the government gradually extends the statutory retirement age to both extend the working periods during which the payroll tax revenue is collected and shorten the periods during which social security benefits are paid. By endogenously determining the retirement age to minimize the social security budget imbalances in each year, the model requires individuals to retire at the age of 75 by the year 2100 .

Figure 8a illustrates impacts on labour supply where people are required to spend more time in the labour force for they will not receive social security benefits until the age of 75. This leads to a greater accumulation of assets that peaks closer to the new retirement age before running down at a more gradual pace due to higher social security benefit pay-out in each year.

In contrast to the option 2, individuals can consume more over the lifetime, strengthened by the increases in disposable income and social security benefits, which will favourably contribute to welfare. 


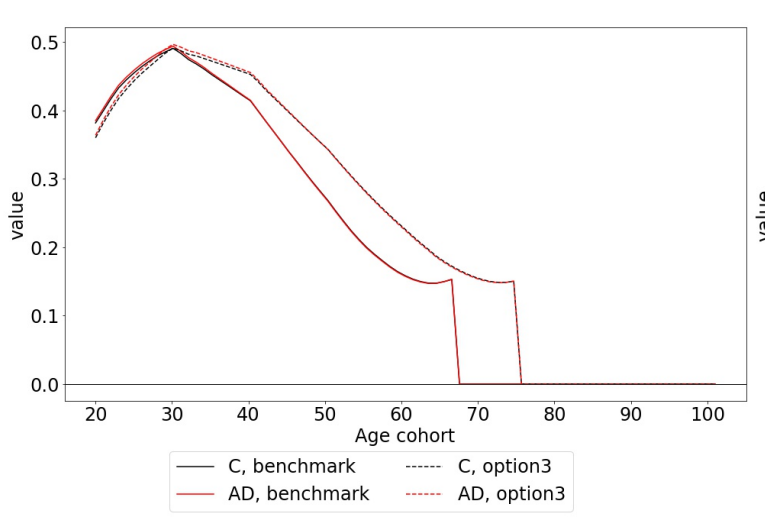

(a) Labour supply

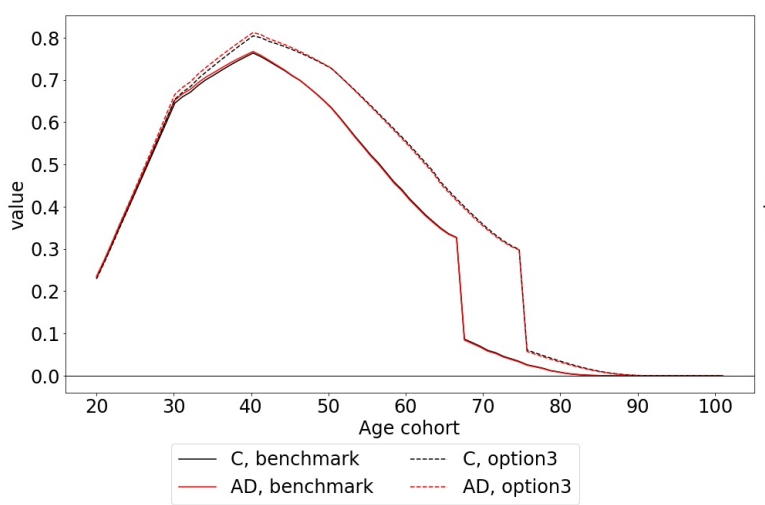

(c) Income

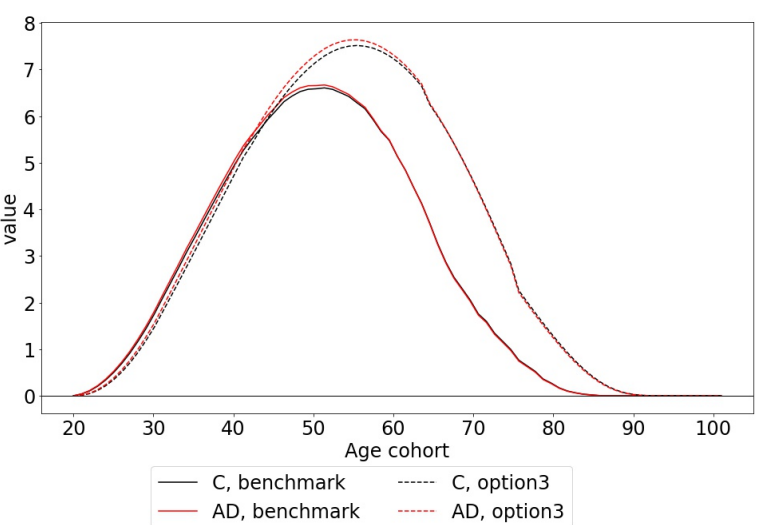

(b) Assets

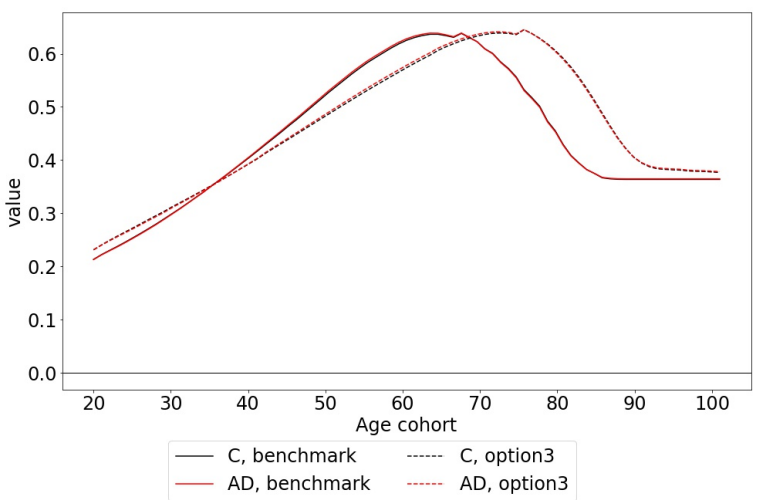

(d) Consumption

Figure 8: Life-cycle profile: Option 3

\subsection{Transition Dynamics}

This section studies the transition dynamics of per-capita variables under different policy options when faced with the median value of population ageing forecast. The percentage deviations of per-capita and policy variables in the year 2100 relative to 2018 are summarized in Table 3. Converting the transition dynamics to that of aggregate variables can be easily done by multiplying the changes in the total population. The transition under the first policy option will serve as a reference when analysing the other two policy alternatives.

\subsubsection{Option 1: Increasing the payroll tax rate}

Figure 9 shows the transition dynamics of per-capita variables under policy option 1 , where the government responds to population ageing by raising the payroll tax rate to sustain its increase in social security spending. Deviations from the benchmark year 2018 with constant and age-dependent risk aversion are represented in black and red lines in each graph respectively, and the benchmark year is marked with the vertical blue line.

As shown in Figure 9a, there is a temporary increase in the capital, which can be explained by the increase in survival rates and the share of a high-saving older population. The capital increase is, however, unsustainable as it contributes, coupled 
Table 3: Long-run macroeconomic effects (Percentage change in the year 2100 relative to 2018 )

\begin{tabular}{lccccccc}
\hline & & \multicolumn{2}{c}{ Option 1 } & \multicolumn{2}{c}{ Option 2 } & \multicolumn{2}{c}{ Option 3 } \\
& & C & AD & C & AD & C & AD \\
\hline Per-capita variables & & & & & & & \\
Labour supply & $\%$ & -9.45 & -9.50 & -2.00 & -1.95 & 3.64 & 3.74 \\
Capital & $\%$ & -5.21 & -5.22 & 13.71 & 14.21 & 14.94 & 15.63 \\
GDP & $\%$ & -7.73 & -7.77 & 4.16 & 4.37 & 8.13 & 8.46 \\
Consumption & $\%$ & -7.15 & -7.17 & -1.00 & -1.00 & 3.98 & 4.05 \\
Wage & $\%$ & 1.89 & 1.91 & 6.29 & 6.46 & 4.34 & 4.55 \\
Interest rate & $\%$ & -0.37 & -0.37 & -1.15 & -1.17 & -0.81 & -0.84 \\
\hline Policy variables & & & & & & & \\
Retirement age & years & 67 & 67 & 67 & 67 & 75 & 75 \\
Labour income tax & $\%$ & 0.26 & 0.27 & 0.21 & 0.23 & -0.07 & -0.06 \\
Social security tax & $\%$ & 9.89 & 9.89 & 0.00 & 0.00 & 0.00 & 0.00 \\
Benefits reduction & $\%$ & 0 & 0 & 42 & 42 & 0 & 0 \\
\hline C and AD represent constant and age-dependent risk aversion assumption respectively
\end{tabular}

with a decline in working-age cohorts, to the higher capital-to-labour ratio, which lowers the interest rate and eventually discourages savings. A decline in savings is also a result of lower disposable income due to higher tax rates. Though minimal, there is a slightly larger decline in capital under an assumption of increasing agedependent risk aversion due to a more considerable drop in precautionary savings from a decline in a share of younger cohorts.

Figure 9b shows a significant decline in per-capita labour supply, reaching $15 \%$ in the long run, due to a shrinkage of the working-age population. Jointly considered with the dynamics of per capita capital earlier, this explains a reduction in GDP per capita in Figure 9c. The magnitude of the labour decline is slightly larger when individuals are increasingly risk averse with age because their higher labour supply amplifies the effect from the shrinkage of younger cohorts.

Dynamics of capital-to-labour ratio lead to an initial increase in capital intensity before it partially decreases and gradually converts to the new equilibrium. This increases wage rate and decreases the return on capital, as shown in Figure 9e and 9f.

Figure $9 \mathrm{~g}$ shows that the social security tax rate needs to increase up to $15 \%$ in the long run to account for a lower tax base and higher benefit pay-outs. Likewise, the labour income tax rate also needs to increase due to lower tax bases from reductions in consumption, income, and asset returns.

On the demand side, Figure $9 \mathrm{~d}$ shows a decrease in consumption that is due to lower disposable earnings, mainly because of the higher income and social security tax rates that subdue the increase in gross wage. 


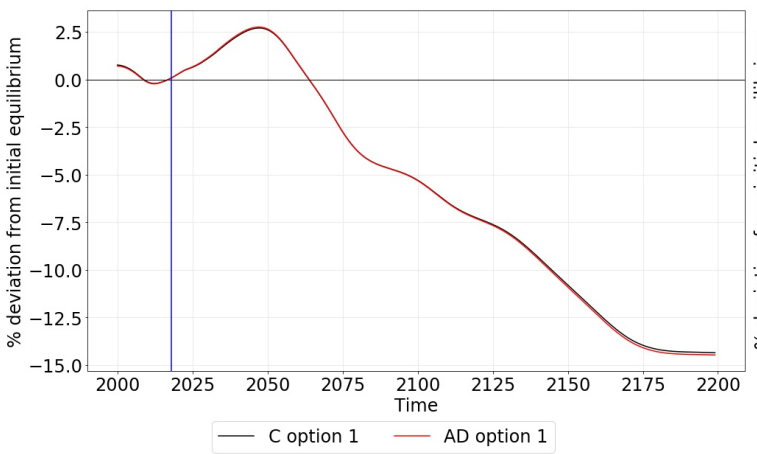

(a) Capital stock per capita

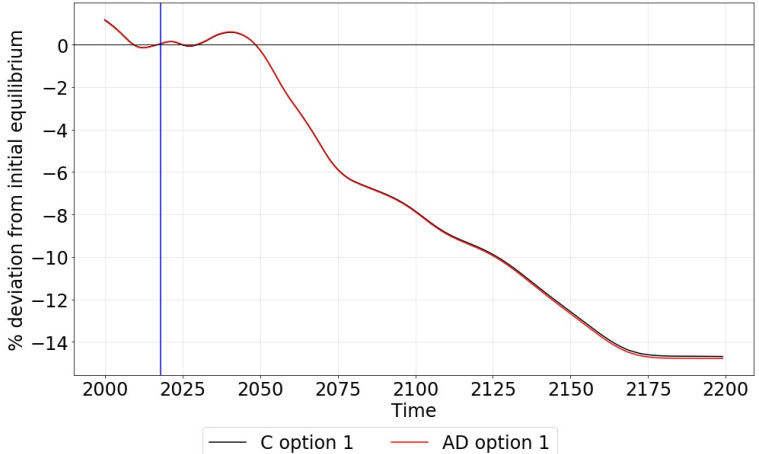

(c) GDP per capita

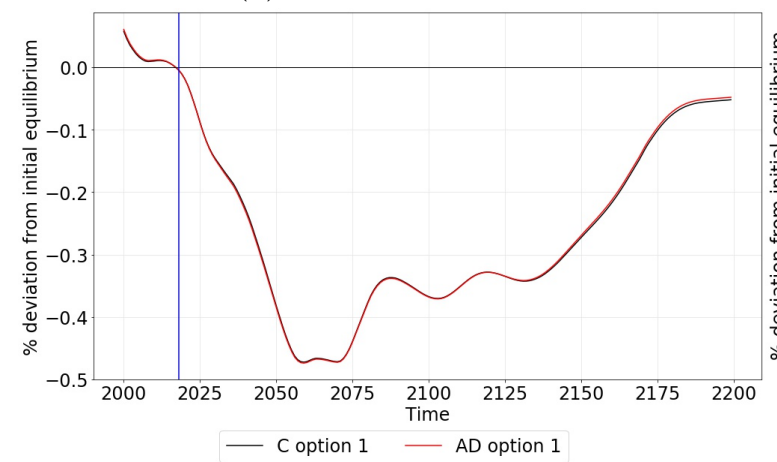

(e) Rate of return

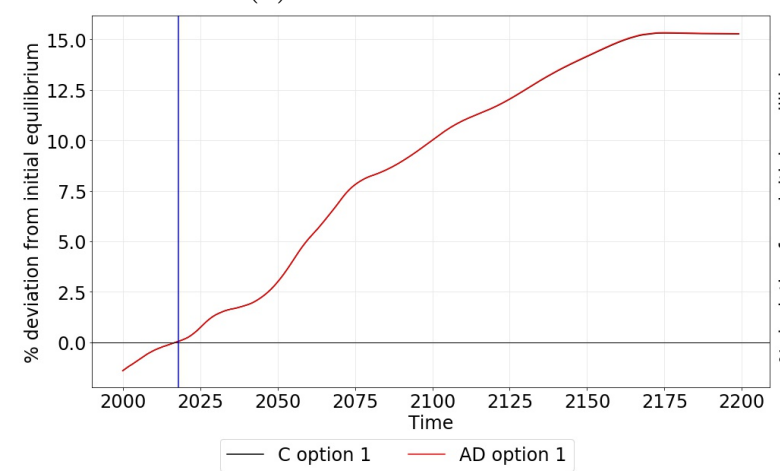

(g) Social security tax rate

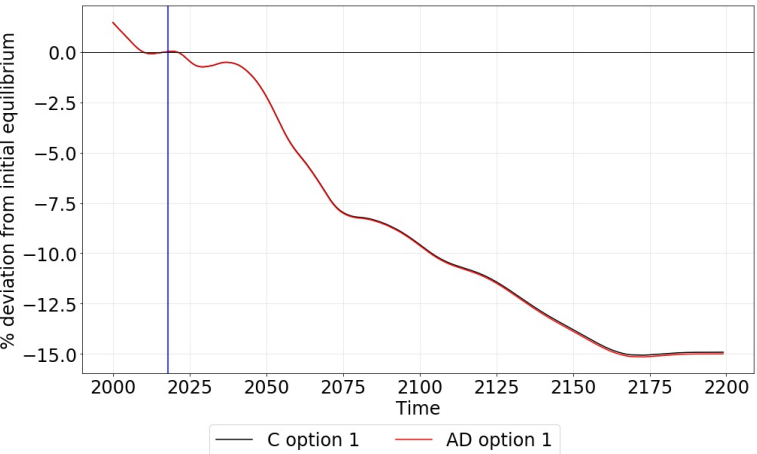

(b) Labour supply per capita

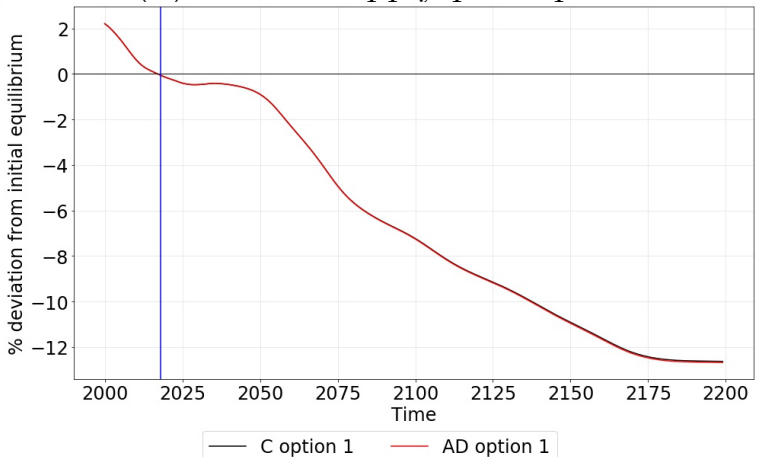

(d) Consumption per capita

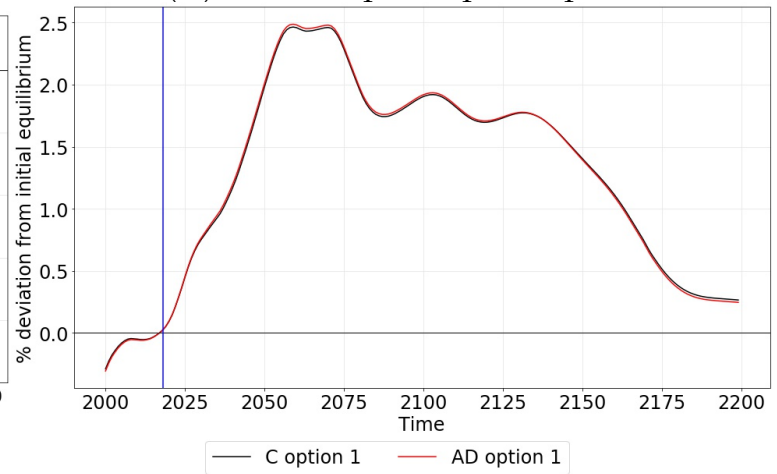

(f) Wage rate

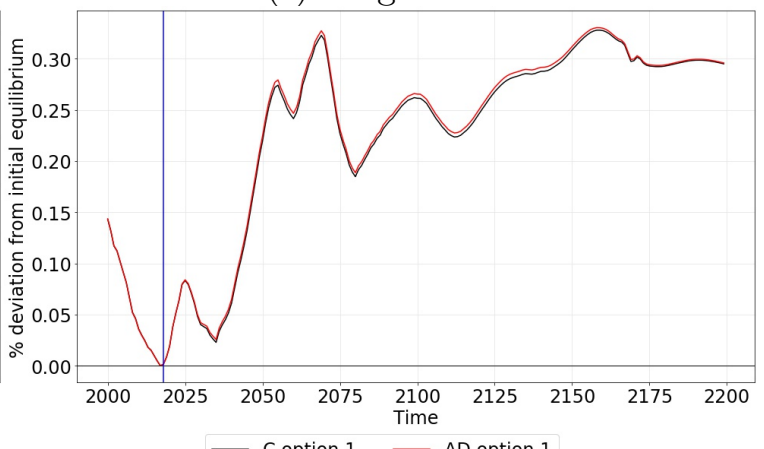

(h) Labour income tax rate

Figure 9: Ageing population transition dynamics under policy option 1 


\subsubsection{Option 2: Cutting social security benefits}

Figure 10 compares the transition dynamics of per-capita economic variables under policy options 2 and 3 to that of option 1.

Suppose the government decides to adopt policy option 2 by proportionally reducing social security benefits. In that case, per-capita capital is expected to be higher than those under the benchmark economy and option 1 as a consequence of savings build-up to compensate for lower social security benefit entitlement. Stronger precautionary savings motive under the age-dependent risk aversion leads to higher capital compared to the constant case.

Figure 10b illustrates that per-capita labour supply reduces by a lesser extent compared to under option 1 . The greater working effort put in to compensate for a reduction social security benefits helps cushion adverse effects from the demographic structural change on the overall workforce. Better dynamics of capital and labour help maintain economic expansion, with a long-run $3 \%$ increase in GDP per capita from the benchmark year compared to a $15 \%$ decline of the first policy option.

In terms of price variables, the capital intensity ratio that monotonically increases results in a lower rate of return on capital and a higher wage rate. The deviations are bigger under the age-dependent risk assumption mainly due to the more positive deviation of capital. The social security tax rate is assumed to stay at the benchmark year's level, whereas labour income tax increases due to the decline in the tax base, mainly from the decrease in working income.

Supported by increases in a wage rate and savings, consumption also improves when compared to option 1, although still slightly lower than the benchmark year.

\subsubsection{Option 3: Extending the retirement age}

To minimize the government social security budget imbalances, the mandatory retirement age under the constant and age-dependent risk aversion assumptions needs to substantially increase, prolonging the period during which people work and accumulate capital which causes per-capita capital stock and labour supply to positively deviate from the benchmark year (Figure 10b and Figure 10a). The improvements in both labour supply and capital contribute favourably to the per capita output, making it the best option in terms of economic growth among the three alternatives. Intuitively, policy option 3 forces labour to work longer and therefore save more to promote economic expansion at the cost of additional strains on the workforce.

Figure $10 \mathrm{e}$ and $10 \mathrm{f}$ show the change in price variables. The large increase in capital per person significantly increases the capital intensity and wage rate, contributing to greater uncertainties, although not as much as under option 2. On the flip side, the return on capital decreases substantially.

The social security tax rate is assumed to be fixed at the benchmark level. However, because an increase in economic activities come mainly from higher capital accumulation and less from an increase in labour supply, the tax base does not sufficiently increase to support government spending, assumed as a fixed proportion of GDP. Therefore labour income tax needs to increase ${ }^{11}$. Nevertheless, overall tax increases from both social security and labour income are smaller than the other two options

\footnotetext{
11 The labour income tax is volatile as an extension of the retirement age is done in a one year increment, requiring the tax rate to adjust to balance the government budget in each period.
} 
which serve as another factor to help support consumption in addition to higher savings and working income.

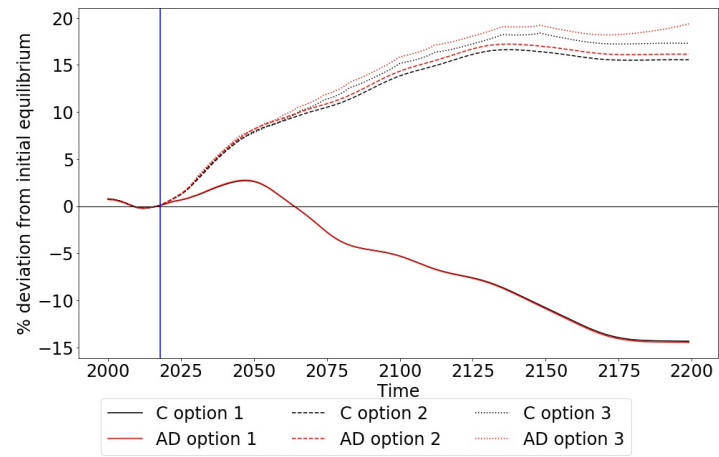

(a) Capital stock per capita

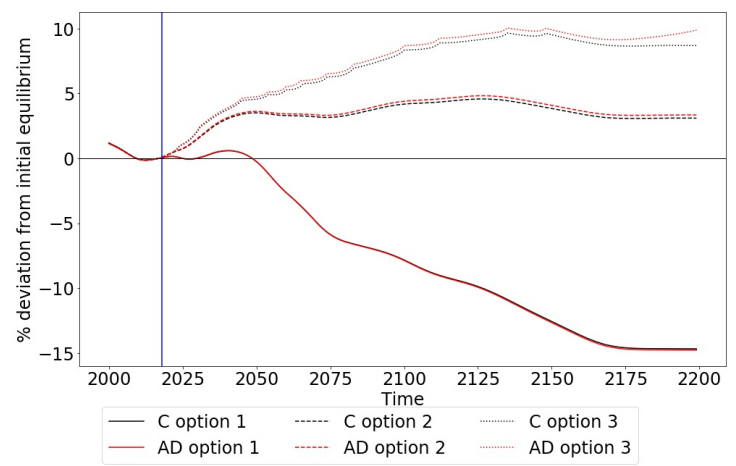

(c) GDP per capita

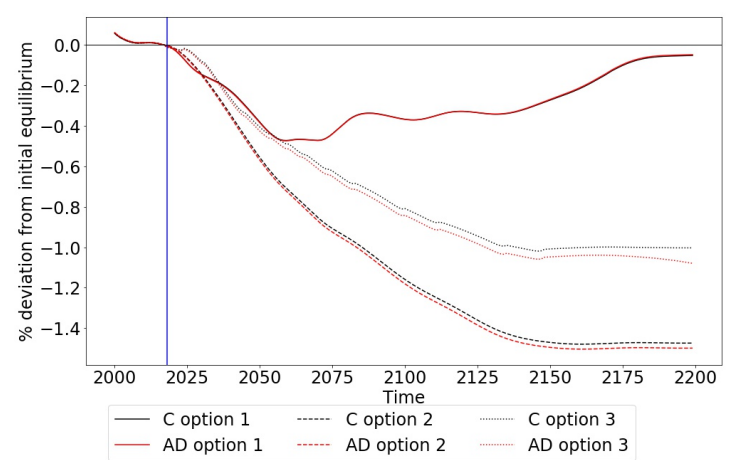

(e) Rate of return

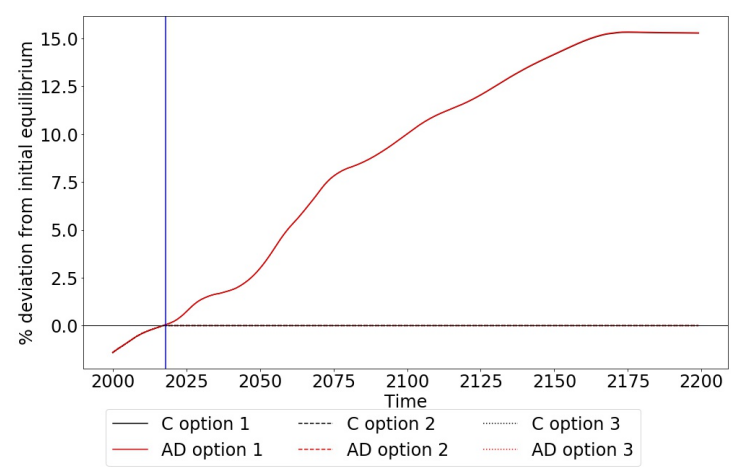

(g) Social security tax rate

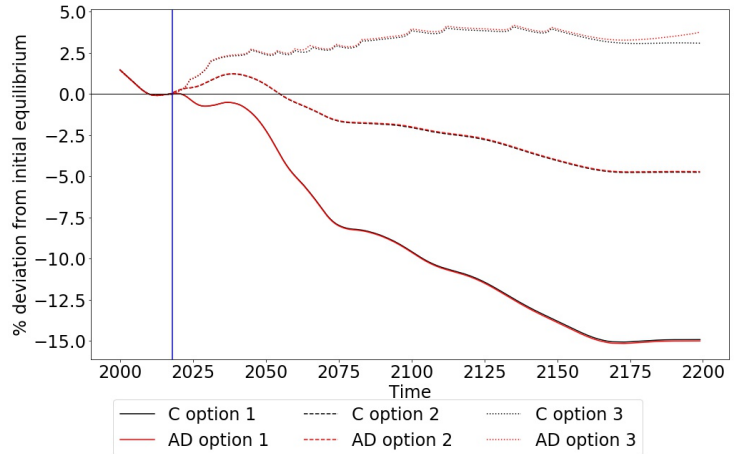

(b) Labour supply per capita

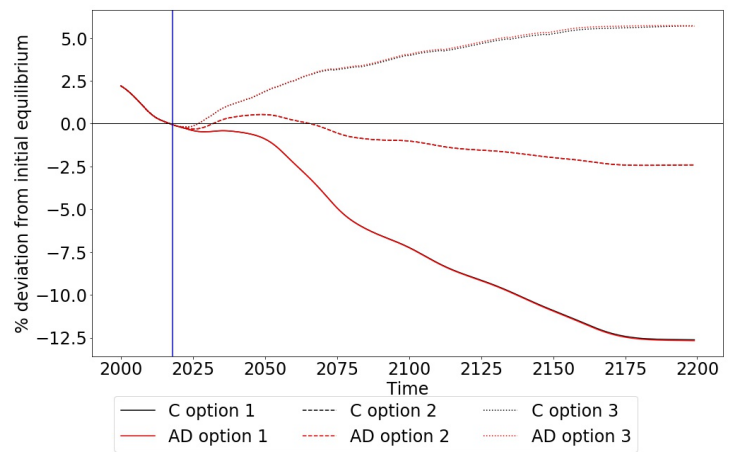

(d) Consumption per capita

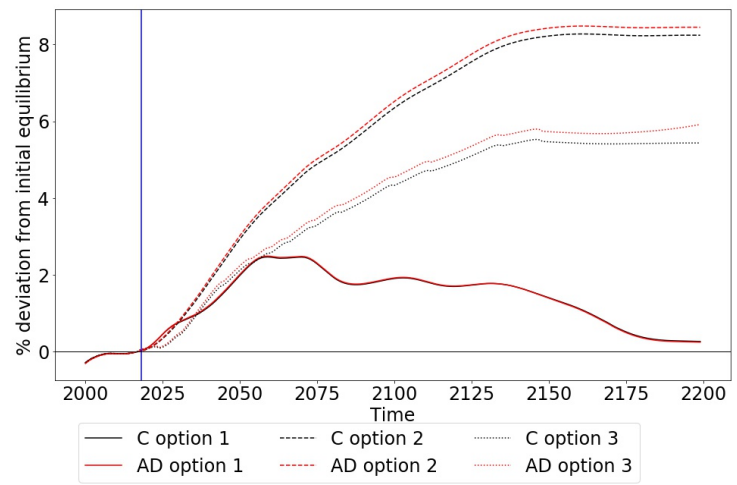

(f) Wage rate

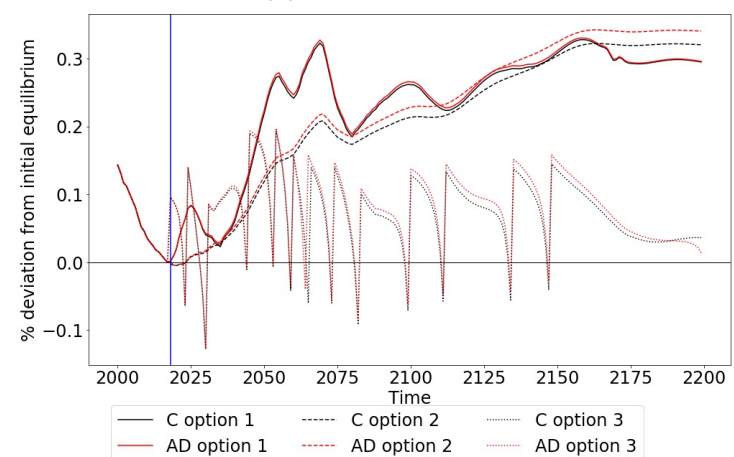

(h) Labour income tax rate

Figure 10: Ageing population transition dynamics under different policy options 


\subsection{Welfare Analysis}

This section evaluates the welfare impacts of current and future cohorts when the government adopts different fiscal policy reforms. Common welfare determinants under both risk aversion assumptions are the changes in life-cycle consumption and leisure caused by the interactions between population ageing and policy feedbacks, the more of each leading to higher welfare. However, with the risk-sensitive preferences, the magnitude of changes in future uncertainties also plays an important role, with higher expected uncertainties lowering the overall welfare to the extent depending on how highly risk averse an individual is at the time. Due to the model structure of this paper, the main source of uncertainty is from how much the future wage rate changes which in turn affects stochastic earnings, the level of consumption and leisure, and ultimately the welfare. One possible explanation is that as people become more risk averse as they get older - e.g., for their diminishing ability to earn extra income on which their retirement spending depends, making them less resilient to income shocks compared to younger adults - they will prefer to have a certain level of income, even at a lower amount, that enables them to plan out their retirement with more certainty. An increase in uncertainties brought about by policy responses to population ageing will, therefore, worsen their overall well-being.

To evaluate the welfare impact, this paper uses Hicksian Equivalent Variation (HEV) to find by what percentage the reference levels of consumption and leisure across all states of an individual's remaining lifetime needs to change so that he or she is equally well-off as compared to after the reform has occurred. The reference under the first policy option is the consumption and leisure in the benchmark year. However, for option 2 and 3, the reference is the consumption and leisure under option 1. A general finding across all policy options is that ageing demographics lead to a reduction in welfare mainly due to the decreases in consumption and leisure, although to different extents based on which policy option is undertaken and what risk aversion assumption is used.

Figure 11 compares the welfare of cohorts that reach the age of 20 after the reform took place to those who are at the age of 20 in the benchmark year. When the government responds to population ageing by raising the payroll tax rate, the welfare of future generations is lower due to lower life-cycle consumption and leisure. During the transition, welfare under the age-dependent increasing risk aversion is slightly lower because heightened uncertainties from an increase in the wage rate aggravate households' future planning. As the uncertainty starts to decrease when the wage rate gradually declines over the long run while the risk-free return increases along with the increase in the life-cycle savings, the welfare under the age-dependent assumption start to exceed its counterpart's. 


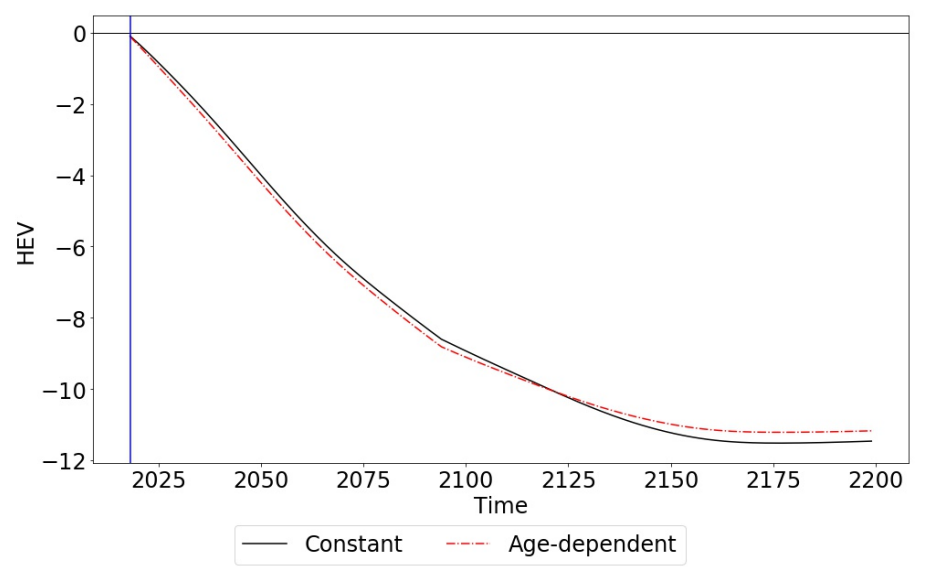

Figure 11: Welfare impacts of future generation under policy option 1

Figures 12 and 13 show the welfare under policy options 2 and 3 evaluated relative to the first policy option for different age cohorts in the year 2019, when the policies take effect, and for the future cohorts who reach the age of 20 after the year 2019 .

There is a trade-off between welfare reduction among the current cohorts and welfare improvement among future generations under policy option 2. Cutting social security benefit lowers current cohorts' welfare compared to the case of raising payroll tax rate (12a) because lower benefits reduce their consumption after retirement and require more work effort which in turn lead to less leisure. However, higher labour supply gradually enables more consumption, causing the welfare of future generation to eventually exceed that of option 1. Smoother life-cycle consumption is also beneficial for households' well-being, as their impatience causes them to prefer evenly spread-out consumption rather than low consumption now and high consumption in the future. The findings under the constant risk aversion assumption are consistent with the studies done by Kitao (2014) and Nishiyama (2015).

However, when people are increasingly risk averse with age, the welfare of both current and future generations under option 2 is lower because of the additional penalty applied from the increased uncertainties arising from a higher wage rate (Figure 10f). This makes the retirement planning more difficult. Therefore, cutting social security benefits may not be as strongly preferred to increasing payroll tax as prior studies have suggested.

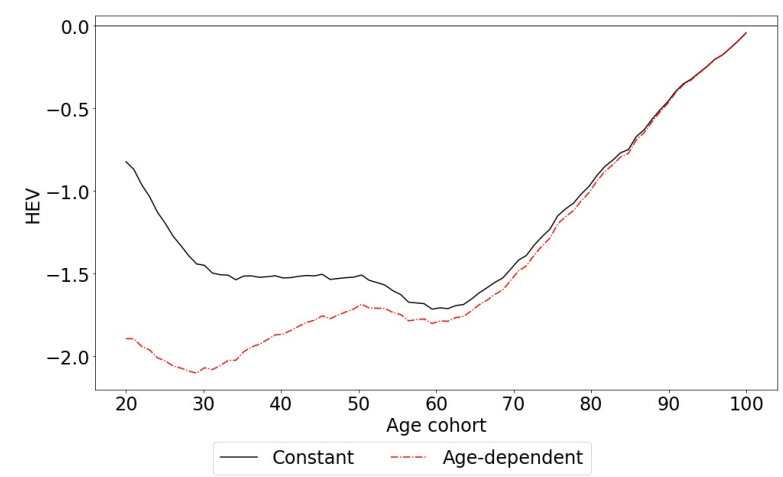

(a) Welfare of current cohorts

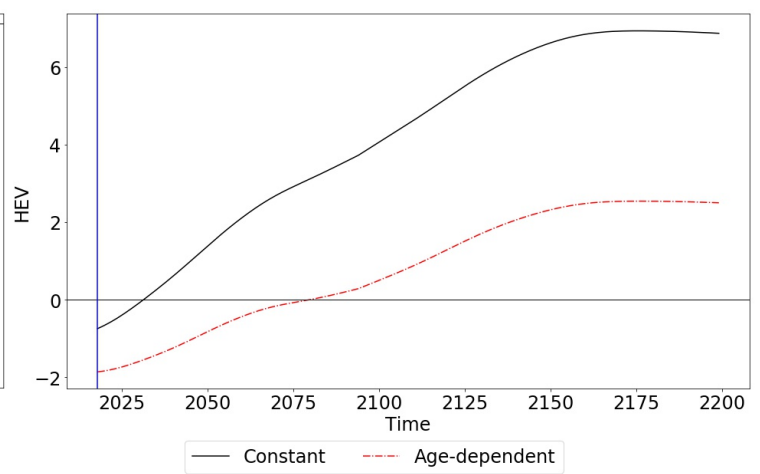

(b) Welfare of future cohorts

Figure 12: Welfare impacts under policy option 2 
Under policy option 3, even though retirement age is endogenously determined to minimize the social security budget imbalances, the goods market still doesn't clear in each year due to the constraint that the retirement age needs to be extended in a one-year increment, causing the welfare changes to be less smooth than other policy options. Similar to option 2, Figure 13a shows that the welfare of the current cohorts is lower than option 1 before gradually improves for future generations. However, the penalty in the age-dependent risk aversion scenario is milder compared to option 2 because extending the retirement age substantially increases labour supply which helps keep the capital-to-labour ratio, the wage rate, and therefore uncertainties more under control.

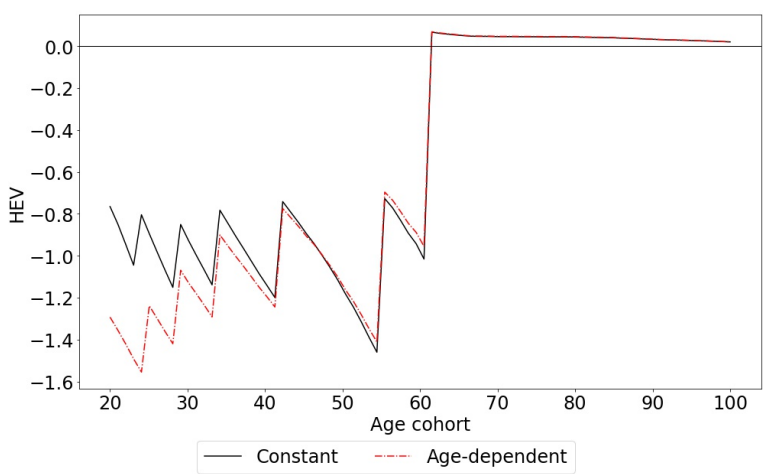

(a) Welfare of current cohorts

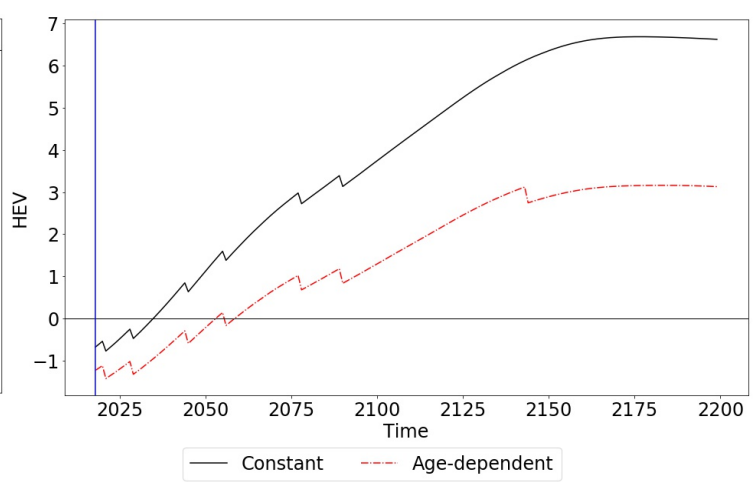

(b) Welfare of future cohorts

Figure 13: Welfare impacts under policy option 3

In summary, the findings here are consistent with what Tallarini Jr (2000) has found in his study on business cycle model without overlapping generations that risk aversion, although doesnt affect the aggregate variable much, increase the welfare cost of uncertainties. Figure 14 suggests that when individuals have constant risk aversion, policy option 1 is the best for the current cohorts in terms of welfare followed by options 2 and 3 respectively. For future generations that reach the age of 20 after the benchmark year, policy options 2 and 3 are equally efficient in terms of welfare improvements, rendering the payroll tax rate increase to be the worst option, consistent with what Kitao (2014) and Nishiyama (2015) have found. In particular, welfare of future generations under option 2 and 3 starts to exceed that under option 1 around the year 2035 and respectively yield $6.9 \%$ and $6.6 \%$ welfare improvements over policy option 1 in the long run.

The assumption of constant risk aversion may underestimate risk aversion of old cohorts and overestimate the risk aversion of young cohorts, leading to inaccurate welfare impacts. The introduction of additional welfare cost from the policy-induced uncertainties under the age-dependent increasing risk aversion causes a social security benefit reduction to be much less favourable compared to an extension of the retirement age. Specifically, it takes until the year 2081 for age-20 individuals under policy option 2 to be better off than policy option 1, whereas it is the year 2060 under option 3. The welfare improvements of option 2 and 3 in the long run are also lowered to $2.5 \%$ and $3.1 \%$ respectively. Policy option 1 is still a clear winner based on current generations' welfare, and policy options 2 and 3 may not be as strongly preferred for future generations as the studies with constant risk aversion have suggested. This 
conclusion holds as long as risk aversion increases with age. Nevertheless, extending retirement age can still be recommended when economic performance is taken into account as it yields the best performance in terms of GDP per capita. In addition, when allowing social security benefits to vary within the same cohort, the welfare of future generations under option 3 also significantly improves (see A.3).

As analysed in Appendix A, the welfare differences between constant and agedependent risk aversion widen when older cohorts are more risk averse compared to the young (A.1), stochastic labour productivity increases (A.2), and when individuals favour consumption to leisure (A.4).

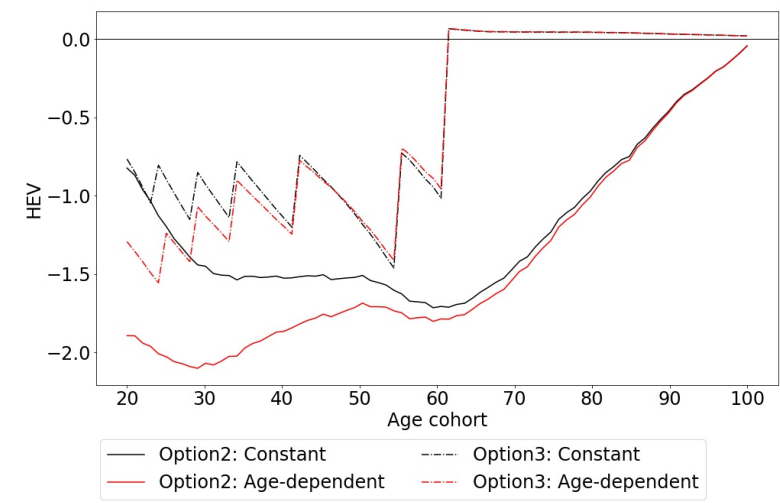

(a) Welfare of current cohorts

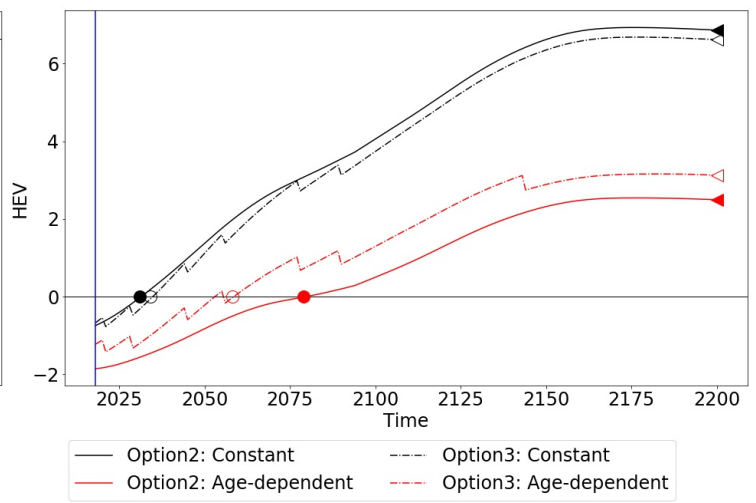

(b) Welfare of future cohorts

Figure 14: Welfare impacts across different policy options

\section{Conclusion}

An overlapping generation model with risk-sensitive preferences and age-dependent increasing risk aversion is developed in this paper to incorporate the aspect of policyinduced uncertainties into the evaluation of welfare impacts of population ageing. This paper has proposed that age heterogeneity in risk aversion is vital as it yields significantly different welfare implications compared to under the widely used constant risk aversion assumption. In addition to conventional aspects of life-cycle consumption and leisure, individuals may be concerned that policy reforms will heighten future uncertainties and make their future planning more challenging, particularly when their capability, whether financially or psychologically, to cope with changes deteriorate with age.

With the constant risk aversion assumption, this study reached the same conclusion found in other studies that reducing social security benefit and extending retirement age results in better social welfare for future generations compared to increasing payroll tax rate, primarily because of the consequent improvement in life-cycle consumption.

However, when individuals are increasingly risk averse with age, welfare implications and the policy efficiency ranking significantly differ, despite small differences regarding life-cycle decisions and transition dynamics. Reducing social security benefits and extending the retirement age results in higher future volatility and makes an individual's retirement planning more difficult compared to the case of increasing payroll taxes. Therefore, reducing social security benefits and extending the retirement age may not be as strongly preferred as previous studies have suggested. 
Compared to reducing benefits, raising the retirement age outperforms both in terms of economic growth and future welfare as it increases life-cycle consumption while not inflating uncertainties as much. This is especially true when allowing social security benefits to vary within the same age cohort. Nevertheless, raising the payroll tax rate still yields the best welfare for the current generations due to its lowest increase in uncertainties among the three policy options. Taken together, these findings suggest coping with population ageing by extending the retirement age if the policy objective were to optimize social welfare as well as economic performance, even though this will come at a higher cost of current generation's welfare deterioration than previously believed.

This present study serves as an initial step to incorporate the aspect of policyinduced uncertainties when evaluating welfare implications and provides policymakers with an alternative framework to assess the appropriateness of policy alternatives. Future research may develop a more realistic framework by taking into account a risky rate of return on capital, intentional bequest motives, and social security benefits that depend on the actual path of workers' historical earnings, for example. 


\section{Appendix}

\section{A Sensitivity analysis}

\section{A.1 Alternative risk aversion assumptions}

Age-dependent increasing risk aversion is the underlying assumption that generates the findings analysed above. This section tests whether the general conclusion still holds with different patterns of risk aversion. Four alternative risk assumptions are considered (Figure 15), keeping the assumption that risk aversion increases with age but changing its slope and magnitude. The first risk aversion alternative (R1) lowers risk aversion by 0.1 across all age groups. The second alternative (R2) increases risk aversion by 0.1 across all age groups. The third alternative (R3) flattens the slope, pivoting around the original population-weighted average of risk aversion, by $50 \%$ and the fourth alternative (R4) steepens the slope by $50 \%$. The constant risk aversion assumption is the population-weighted average value of age-dependent risk aversion under each respective case.

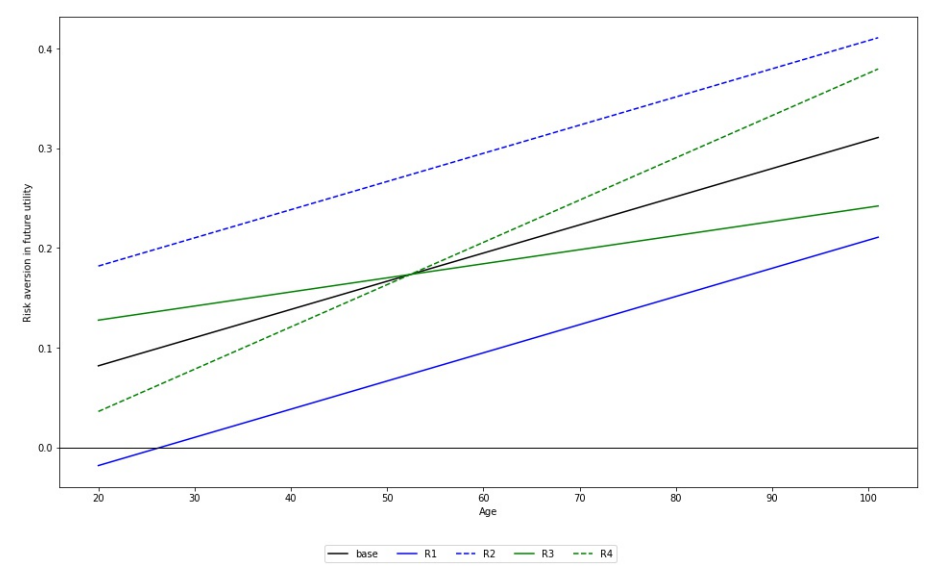

Figure 15: Alternative risk aversion scenarios

Figure 16 shows the welfare of the current and future generations under each risk aversion assumption. In the graphs showing future welfare, a comparison to the main results can be easily observed with the help of corresponding ovals, showing the original year where the welfare of policy options 2 and 3 starts to exceed that of option 1, and the triangles, showing the long-run level of each option in the main result. Compared to constant risk aversion, all alternatives R1-R4 suggest that reducing social security benefits and extending the retirement age generate lower welfare relative to increasing the payroll tax rate. When compared to the main results, scenarios R1 and R3 result in welfare improvements under policy options 2 and 3 relative to option 1. Put differently, it takes less time for people to be better off when the government decides to extend retirement age or to cut social security benefit compared to the case where the government were to increase payroll taxes. The opposite is true for alternative $\mathrm{R} 2$ and $\mathrm{R} 4$.

The key determinant of the extent to which welfare under the age-dependent assumption deviates from that of the constant is how much more risk averse older cohorts 
are, in percentage term, compared to the young. If the difference is big, a constant risk assumption will significantly underestimate the degree of risk aversion of the old and overestimate that of the young. Coupled with life-cycle uncertainties reaching the peak around the retirement age after transitory earning shocks have accumulated, the more underestimation of old cohort risk aversion, the greater the result understates dissatisfaction from the welfare volatility.

The magnitude of shifts in risk aversion (as in R1 and R2) is not as important as the percentage difference between the cohorts risk aversion. For instance, R1 uniformly increases the value of risk aversion, holding the absolute difference between the olds and the youngs value of risk aversion constant. This leads to the smaller relative difference in risk aversion between different age group and therefore dampens the relative misspecification and its adverse impacts. 


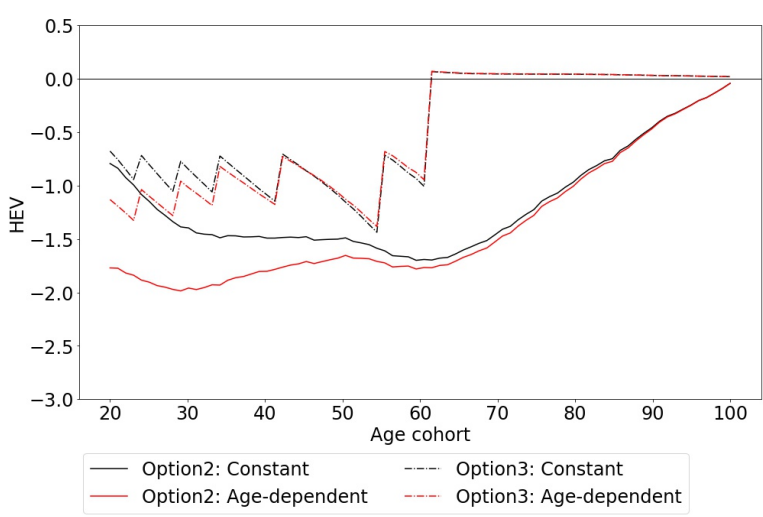

(a) Lower risk by $50 \%$, current generations

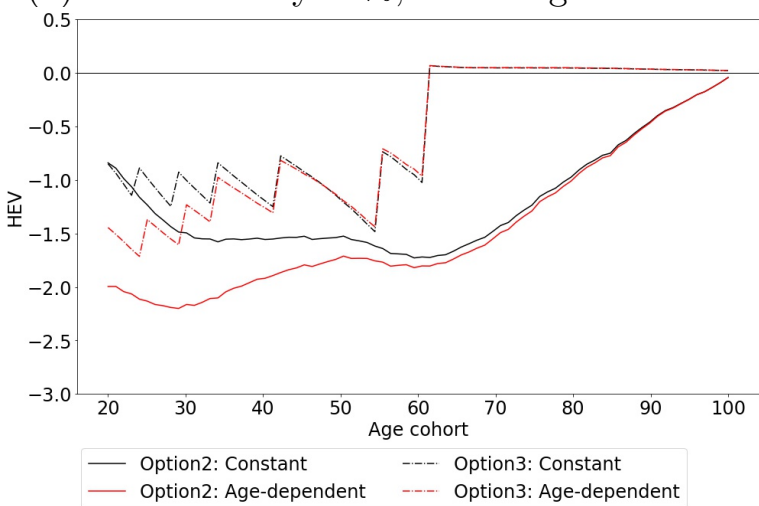

(c) Increase risk by $50 \%$, current generations

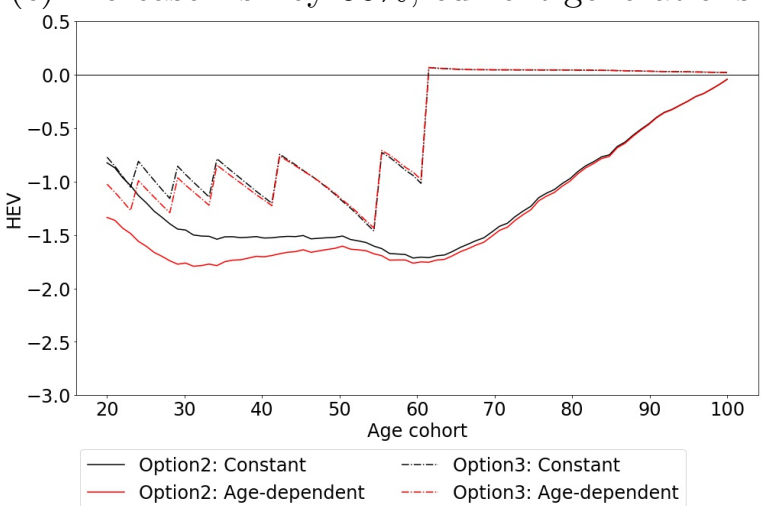

(e) Reduce the slope $50 \%$, current generations
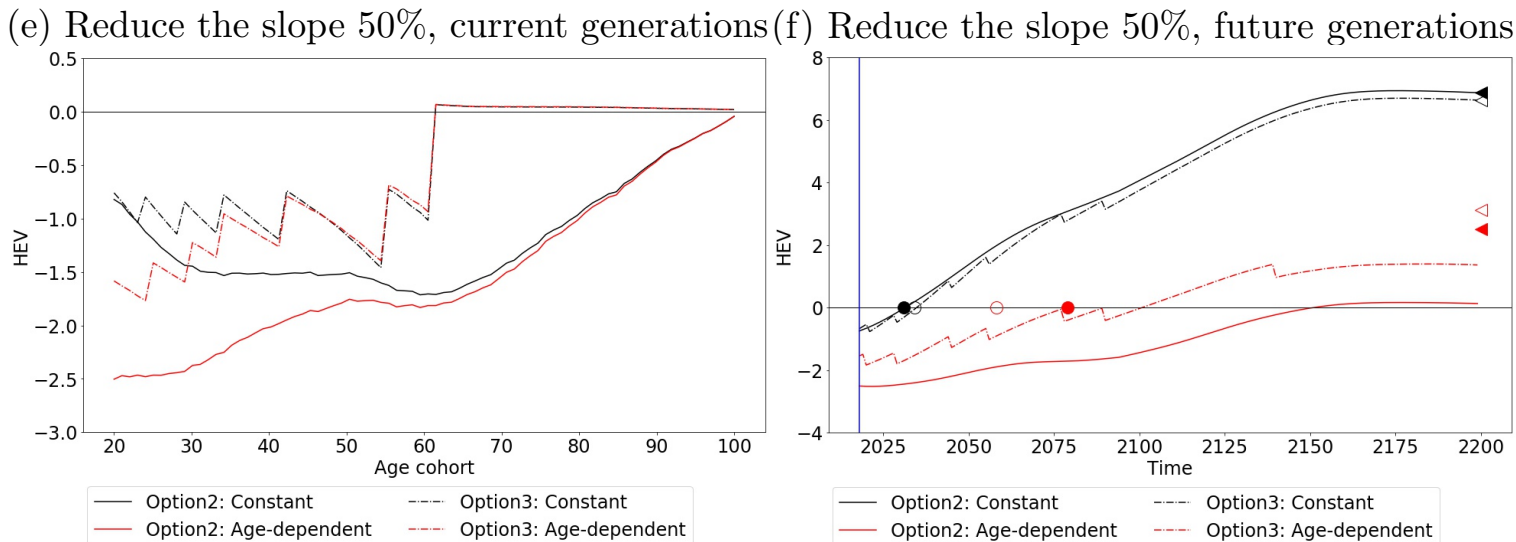

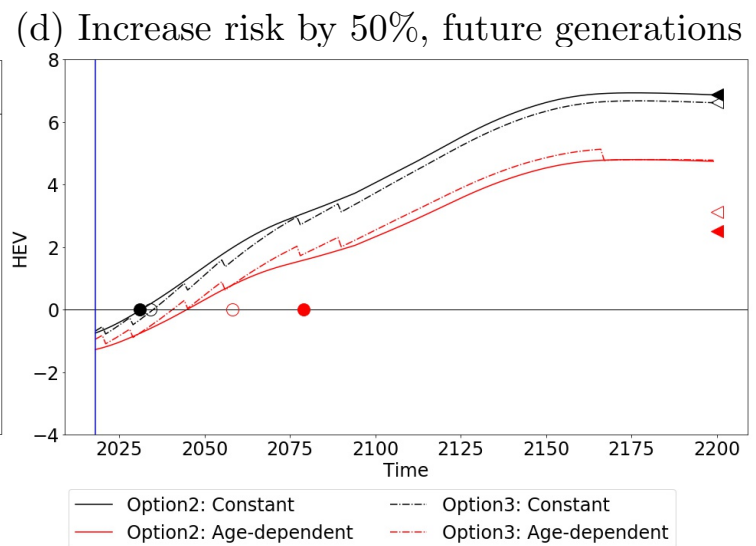

(b) Lower risk by $50 \%$, future generations

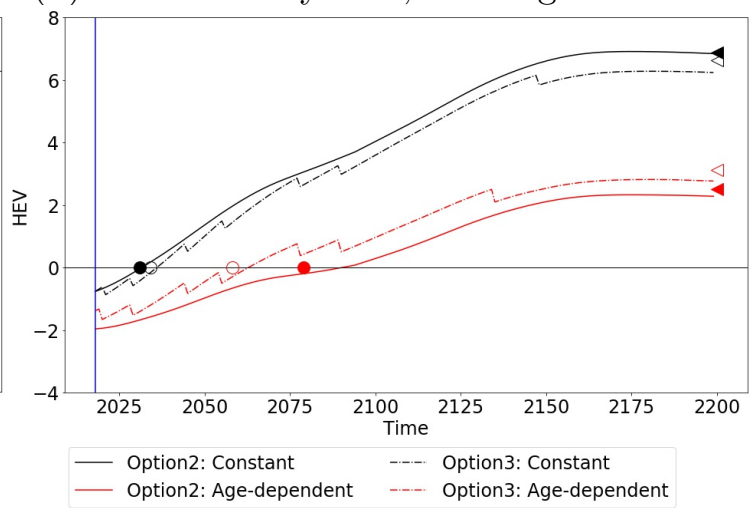

(d) Increase risk by $50 \%$, future generations

(g) Increase the slope 50\%, current generations(h) Increase the slope 50\%, future generations

Figure 16: Welfare impacts under alternative risk assumption 


\section{A.2 Idiosyncratic labour productivity}

In the main analysis, stochastic labour productivity targets the log labour earnings follows the 2004 empirical study of Storesletten et al. (2004) which estimates the data from the year 1969 to 1992 . However, several studies have documented an increase in cohort earnings inequality over time (for instance, Huggett (1996) and Creedy and Hart (1979)). The value used in the main analysis may, therefore, be too low for the benchmark year and also does not take into account the increasing trend for the entire forecasting period.

As an exercise, this section tests the welfare results when earning volatility increases. Referring to Heathcote et al. (2010), log earning volatility can increase by $60 \%$ over a period of 30 years. A conservative assumption of $20 \%$ increase is used here. As expected, the welfare under policy options 2 and 3 worsens compared to the main results because, holding risk aversion assumption constant, individual's life planning gets harder with higher uncertainties.

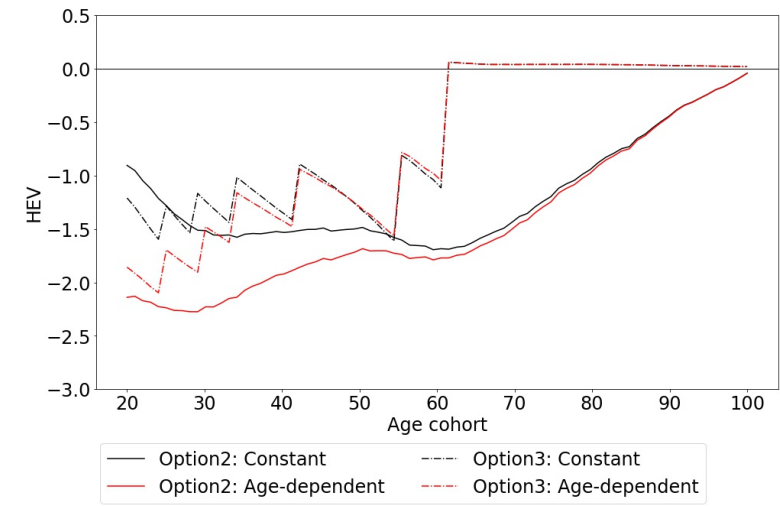

(a) High $\nu$, current generations

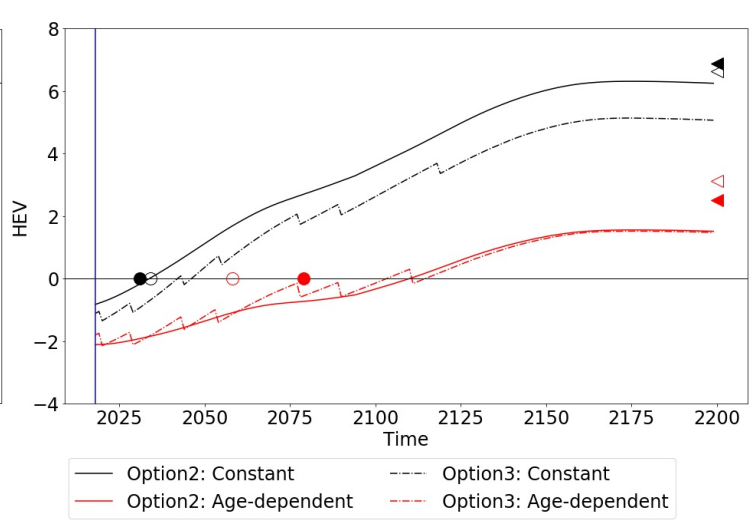

(b) High $\nu$, future generations

Figure 17: Welfare impacts under alternative preference assumption

\section{A.3 Distribution of social security benefits}

The main analysis simplifies the aspect of social security benefits such that all individuals who retire in the same year will get the same benefit payout calculated according to equation (47) - (49). However, actual retirees will receive varying social security benefit depending on their historical earnings. Keeping track of all AIME is however impossible because of the large state space that exponentially increases with time.

To approximate the distribution of AIME, I assume that the expected social security benefits calculated from the model has the same distribution as in the actual SSA's current-pay benefits of the year $2018^{12}$. With this assumption, the distribution of the retired cohorts becomes

\footnotetext{
12 The distribution used in the model is calculated from the Table 5.B6 in the SSA's Annual Statistical Supplement 2019. To keep the calculation simple, identical discretised distribution is used for all education levels.
} 


$$
\phi\left(x_{t+1}=\left\{j+1, a_{t+1}^{j+1}\left(x_{t}\right), \theta^{\prime}, \eta^{\prime}, e^{\prime}, \kappa^{\prime}\right\}\right)=\int_{A \times \Theta \times H \times \mathcal{K}} a_{t+1}^{j+1}\left(x_{t}\right) \cdot d \phi\left(x_{t}=\{j, a, \theta, \eta, e, \kappa\}\right) \cdot \phi(\chi)
$$

, with $\chi \in \mathbb{K}=[0, \infty)$ and $\phi(\chi)$ is the distribution probability of $\chi$.

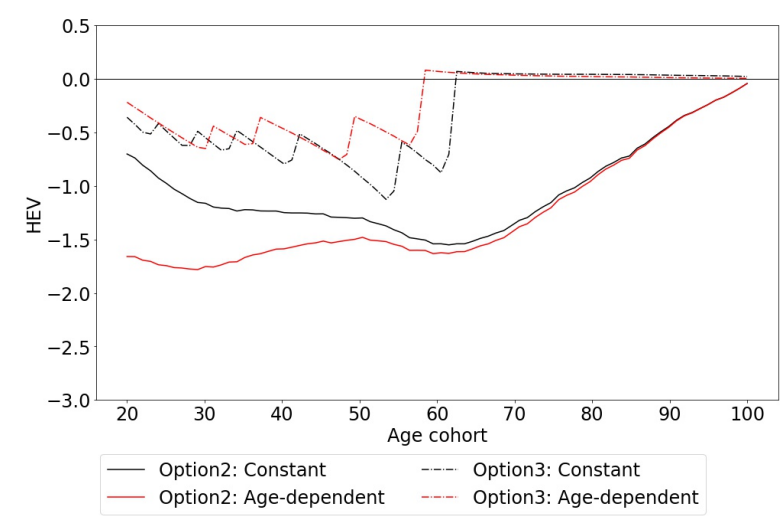

(a) Current generations

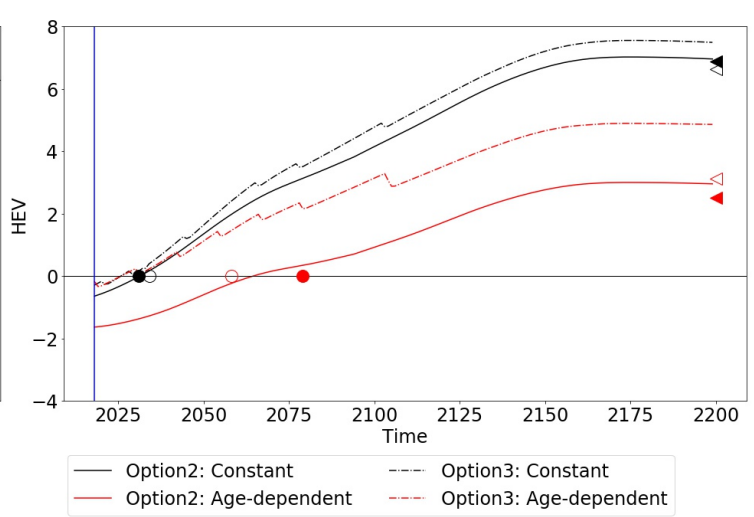

(b) Future generations

Figure 18: Welfare impacts with social security distribution

Figure 18 illustrates the welfare impacts with social security benefit distributions. Introducing uncertainties into social security benefit accentuates the role of age-dependent risk aversion as highly risk averse old cohorts are more affected by additional uncertainties.

However, when evaluating welfare in relative term, by comparing different policy options on the same basis of social security distribution, the welfare of both current and future generations under policy option 2 relative to the first policy option is quite similar to the case with deterministic benefits. This is because approximately the same extents of extra uncertainties are present in all policy options.

Nevertheless, there is a significant welfare improvement under policy option 3. Before adding extra uncertainties in benefits, extending the retirement age forces people who previously earn deterministic benefits to be exposed to earning risk, hence lowers their welfare. Once uncertainties in benefits are already present after retirement, the marginal risk from extending the retirement age is not as big, resulting in less welfare penalty. Despite the simplified assumption of social security distribution used, the results here further support extending the retirement age.

\section{A.4 Preferences}

Figure 19 shows the welfare change when individual favour more consumption than what is considered in the main analysis, represented by a $10 \%$ increase in the taste parameter towards consumption $\nu$. It now takes longer for the welfare under policy option 2 to exceed that of option 1 . The willingness to work harder to increase available resources for consumption means that demographic redistribution from young to old will result in greater impacts on the overall labour supply and therefore the capital intensity and wage. Greater changes in wage subsequently result in higher uncertainties which worsen the overall welfare. 


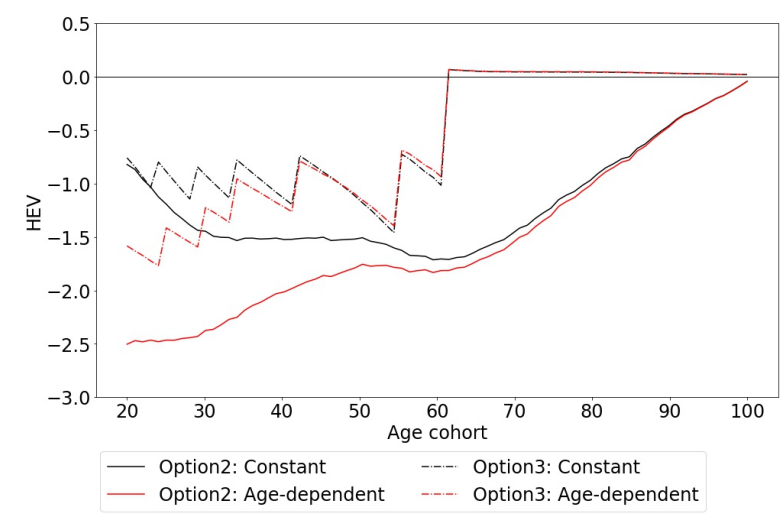

(a) High $\nu$, current generations

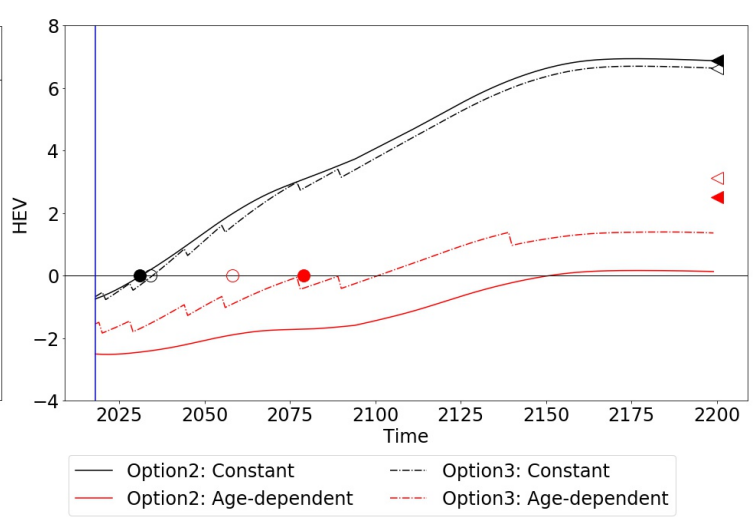

(b) High $\nu$, future generations

Figure 19: Welfare impacts under alternative preference assumption

\section{B Computation}

The solution method discretises individual states $\{a, \theta, \eta\}$ to simplify the nonlinear dynamic programming problem. Macroeconomic solutions are solved with a GaussSeidel procedure by Auerbach and Kotlikoff (1987) and individual policy functions are solved backwards by microeconomic numerical solutions including a Newton method and interpolation algorithms. The computation steps for the stationary equilibrium can be summarized below

1. Initializes parameters and discretizes state space.

2. Calculates price variables according to (35) and (36).

3. Uses a numerical maximization and interpolation algorithm to solve for policy functions $a_{t+1}^{t+1}\left(x_{t}\right), c_{t}^{j}\left(a_{t+1}^{t+1}\right)$, and $l_{t}^{j}\left(a_{t+1}^{t+1}\right)$ that satisfy the household optimal decision represented in $(30)$.

4. Consequent policy functions are then used to solve for household distributions over state space.

5. State-specific values are aggregated into age-cohort variables and aggregate variables consistent with policy functions and distribution.

6. Update the government policy schedules according to alternative policies considered.

7. Calculate social security benefits according to (47)-(49).

8. Updates price variables and iterates from step 2 until all markets clear. 


\section{References}

Albert, S. M., and Duffy, J. (2012). Differences in risk aversion between young and older adults. Neuroscience and neuroeconomics, 2012(1).

Altig, D., Auerbach, A. J., Koltikoff, L. J., Smetters, K. A., and Walliser, J. (2001). Simulating fundamental tax reform in the united states. American Economic Review, $91(3), 574-595$.

Arrow, K. J. (1965). Aspects of the theory of risk-bearing. Yrjö Jahnssonin Säätiö.

Auerbach, A. J., and Kotlikoff, L. J. (1987). Dynamic fiscal policy. Cambridge University Press.

Bellante, D., and Green, C. A. (2004). Relative risk aversion among the elderly. Review of Financial Economics, 13(3), 269-281.

Blume, M. E., and Friend, I. (1975). The asset structure of individual portfolios and some implications for utility functions. The Journal of Finance, 30(2), 585-603.

Bommier, A., and Grand, F. L. (2018). Risk aversion and precautionary savings in dynamic settings. Management Science.

Bommier, A., Harenberg, D., Le Grand, F., and ODea, C. (2020). Recursive preferences, the value of life, and household finance.

Bommier, A., Kochov, A., and Le Grand, F. (2017). On monotone recursive preferences. Econometrica, 85(5), 1433-1466.

Chen, X., Favilukis, J., and Ludvigson, S. C. (2013). An estimation of economic models with recursive preferences. Quantitative Economics, 4(1), 39-83.

Conine, T. E., McDonald, M. B., and Tamarkin, M. (2017). Estimation of relative risk aversion across time. Applied Economics, 49(21), 2117-2124.

Creedy, J., and Hart, P. E. (1979). Age and the distribution of earnings. The Economic Journal, 89(354), 280-293.

DaSilva, A., Farka, M., and Giannikos, C. (2019). Age-dependent increasing risk aversion and the equity premium puzzle. Financial Review, 54(2), 377-412.

De Nardi, M., Imrohoroğlu, S., and Sargent, T. J. (1999). Projected us demographics and social security. Review of Economic dynamics, 2(3), 575-615.

Dohmen, T., Falk, A., Huffman, D., Sunde, U., Schupp, J., and Wagner, G. G. (2011). Individual risk attitudes: Measurement, determinants, and behavioral consequences. Journal of the European Economic Association, 9(3), 522-550.

Epstein, L., and Zin, S. (1989). Substitution, risk aversion, and the temporal behavior of consumption and asset returns: A theoretical framework. Econometrica, 57(4), 937-69. 
French, E. (2005). The effects of health, wealth, and wages on labour supply and retirement behaviour. The Review of Economic Studies, 72(2), 395-427.

Giandrea, M. D., and Sprague, S. A. (2017). Estimating the us labor share. Monthly Labor Review.

Gottardi, P., Kajii, A., and Nakajima, T. (2015). Optimal taxation and debt with uninsurable risks to human capital accumulation. American Economic Review, $105(11), 3443-70$.

Halek, M., and Eisenhauer, J. G. (2001). Demography of risk aversion. Journal of Risk and Insurance, 1-24.

Hansen, G. D. (1993). The cyclical and secular behaviour of the labour input: Comparing efficiency units and hours worked. Journal of Applied Econometrics, 8(1), 71-80.

Hansen, L. P., Heaton, J. C., and Li, N. (2008). Consumption strikes back? measuring long-run risk. Journal of Political economy, 116(2), 260-302.

Hansen, L. P., and Sargent, T. J. (1995). Discounted linear exponential quadratic gaussian control. IEEE Transactions on Automatic control, 40(5), 968-971.

Heathcote, J., Storesletten, K., and Violante, G. L. (2010). The macroeconomic implications of rising wage inequality in the united states. Journal of political economy, $118(4), 681-722$.

Holt, C. A., and Laury, S. K. (2002). Risk aversion and incentive effects. American economic review, 92(5), 1644-1655.

Huggett, M. (1996). Wealth distribution in life-cycle economies. Journal of Monetary Economics, 38(3), 469-494.

Huggett, M., and Ventura, G. (1999). On the distributional effects of social security reform. Review of Economic Dynamics, 2(3), 498-531.

İmrohoroglu, A., Imrohoroglu, S., and Joines, D. H. (1995). A life cycle analysis of social security. Economic theory, 6(1), 83-114.

Kitao, S. (2014). Sustainable social security: Four options. Review of Economic Dynamics, 17(4), 756-779.

Kotlikoff, L. J., Smetters, K., and Walliser, J. (1999). Privatizing social security in the united statescomparing the options. Review of Economic Dynamics, 2(3), $532-574$.

Kreps, D. M., and Porteus, E. L. (1978). Temporal resolution of uncertainty and dynamic choice theory. Econometrica: journal of the Econometric Society, 185200.

Meyer, D. J., and Meyer, J. (2005). Relative risk aversion: What do we know? Journal of Risk and Uncertainty, 31(3), 243-262. 
Morin, R.-A., and Suarez, A. F. (1983). Risk aversion revisited. The journal of finance, 38(4), 1201-1216.

Nishiyama, S. (2015). Fiscal policy effects in a heterogeneous-agent olg economy with an aging population. Journal of Economic Dynamics and Control, 61, 114-132.

Nishiyama, S., and Smetters, K. (2007). Does social security privatization produce efficiency gains? The Quarterly Journal of Economics, 122(4), 1677-1719.

Pålsson, A.-M. (1996). Does the degree of relative risk aversion vary with household characteristics? Journal of economic psychology, 17(6), 771-787.

Pratt, J. W. (1964). Risk aversion in the small and in the large'. Econometrica, 32(1-2).

Riley Jr, W. B., and Chow, K. V. (1992). Asset allocation and individual risk aversion. Financial Analysts Journal, 48(6), 32-37.

Roalf, D. R., Mitchell, S. H., Harbaugh, W. T., and Janowsky, J. S. (2011). Risk, reward, and economic decision making in aging. Journals of Gerontology Series B: Psychological Sciences and Social Sciences, 67(3), 289-298.

Storesletten, K., Telmer, C. I., and Yaron, A. (2004). Consumption and risk sharing over the life cycle. Journal of monetary Economics, 51 (3), 609-633.

Swanson, E. T. (2018). Risk aversion, risk premia, and the labor margin with generalized recursive preferences. Review of Economic Dynamics, 28, 290-321.

Tallarini Jr, T. D. (2000). Risk-sensitive real business cycles. Journal of monetary Economics, 45(3), 507-532.

Vogel, E., Ludwig, A., and Börsch-Supan, A. (2017). Aging and pension reform: extending the retirement age and human capital formation. Journal of Pension Economics \& Finance, 16(1), 81-107.

Weil, P. (1990). Nonexpected utility in macroeconomics. The Quarterly Journal of Economics, 105(1), 29-42.

Weil, P. (1993). Precautionary savings and the permanent income hypothesis. The Review of Economic Studies, 60(2), 367-383. 